Discussion Paper No. 13-068

\title{
Financial Sector-Output Dynamics in the Euro Area: Non-linearities Reconsidered
}

Frauke Schleer and Willi Semmler

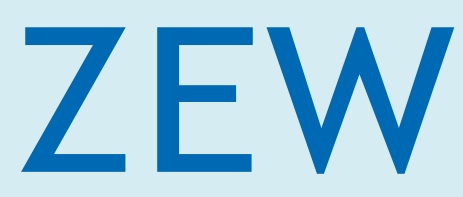

Zentrum für Europäische Wirtschaftsforschung $\mathrm{GmbH}$ Centre for European Economic Research 
Discussion Paper No. 13-068

\title{
Financial Sector-Output Dynamics in the Euro Area: Non-linearities Reconsidered
}

\author{
Frauke Schleer and Willi Semmler
}

Download this ZEW Discussion Paper from our ftp server:

http://ftp.zew.de/pub/zew-docs/dp/dp13068.pdf

Die Discussion Papers dienen einer möglichst schnellen Verbreitung von neueren Forschungsarbeiten des ZEW. Die Beiträge liegen in alleiniger Verantwortung der Autoren und stellen nicht notwendigerweise die Meinung des ZEW dar.

Discussion Papers are intended to make results of ZEW research promptly available to other economists in order to encourage discussion and suggestions for revisions. The authors are solely responsible for the contents which do not necessarily represent the opinion of the ZEW. 


\section{Non-technical Summary}

The financial and economic crisis has stressed the need for a better understanding of destabilizing effects, in particular arising from the financial sector, and how these may spill over to economic activity. In turn, weakening economic conditions are likely to feed back to the financial sector, giving rise to a so-called adverse feedback loop.

So far lacking is work on non-linear linkages and asymmetric dynamics as they may unfold over time. For instance, the magnitude to which financial sector instabilities affect economic activity could depend on the actual state of the financial sector which is more severe at some downswings than others. Thus, non-linearities might not matter much for a long time period but then may generate a rare and large event.

In our empirical work we analyze the feedback mechanisms between economic downturns and financial stress for selected euro area countries as they may appear at some time periods. The hitherto theoretical and empirical findings suggest the need for an empirical approach that can accommodate varying dynamic patterns across alternative states of the economy. We propose a non-linear multivariate Vector Smooth Transition Autoregressive (VSTAR) model framework which has not been used empirically so far. In contrast to previous studies it is able to capture smooth regime changes which we expect in the financial market-output nexus. Our contribution is threefold: first, we use financial condition indices which are more comprehensive and put a stronger focus on the banking sector. Second, we apply a non-linear VSTAR model which has not been used before. We think it is more appropriate to model the relationship between output and the financial sector since it allows for smooth regime changes. Third, we comprehensively investigate the (potentially changing) dynamics between the financial sector and the real economy over time.

In most countries, a shock in the financial market leads to a long-lasting negative response in economic activity which is regime-dependent. Yet, the negative response is not as pronounced as it is in some other studies. This may first result from regime changes taking place rather smooth than abrupt. Shocks in the presence of smooth regime-changing may be dampened so that the negative effect on economic activity is weaker. Second, the outcomes hinge centrally on the sample period. We show that dynamics in the financial market-macroeconomy link vary over time in the euro area countries. Linearity cannot be rejected for some euro area countries over time questioning non-linearities in the financial sector-output nexus as unambiguous feature. Our results point towards increasing importance of non-linearities with the financial crisis break out. Even if linearity is rejected, the negative output effect typically observed is not always present. In particular, it is not continually found before the Lehman collapse, although we are in a model-defined high stress regime. This suggests that events leading to a strong economic breakdown are rather related to a financial cycle which has low frequency and hence, occur rarely. 


\section{Das Wichtigste in Kürze}

Die Finanz-und Wirtschaftskrise hat die Notwendigkeit für ein besseres Verständnis von destabilisierenden Effekten des Finanzsektors und deren Auswirkung auf die reale Ökonomie verdeutlicht. Umgekehrt kann aber auch die schlechte Wirtschaftslage wiederum Druck auf den Finanzsektor ausüben, was zu weiteren negativen Feedbackeffekten führen kann.

Bisher fehlen empirische Analysen, die nicht-lineare Zusammenhänge und asymmetrische Dynamiken im Zeitverlauf, untersuchen. Beispielsweise könnte die Intensität der NichtLinearitäten vom derzeitigen Zustand des Finanzmarktsektors abhängen und je nach Lage negativere Effekte auf die reale Ökonomie zur Folge haben. So könnten NichtLinearitäten über einen langen Zeitraum keine große Rolle spielen, aber dann seltene und große (Wirtschafts-)Krisen generieren.

In unserer empirischen Analyse untersuchen wir die Feedback-Mechanismen zwischen der makrokonomischen Entwicklung und dem Finanzmarktsektor in ausgewählten Ländern des Euroraums und wie sie sich über einen längeren Zeitraum verhalten. Wir verwenden ein nicht-lineares multivariates "Vector Smooth Transition Autoregressive" (VSTAR) Modell, welches in der bisherigen Literatur noch nicht verwendet wurde. Im Gegensatz zu anderen Modellen ist dieses in der Lage, glatte Regimewechsel zu modellieren. Wir gehen davon aus, dass der Übergang von einem zum anderen Regime eher schrittweise als abrupt verläuft. Wir erweitern die bisherigen Erkenntnisse um drei Aspekte: Erstens verwenden wir neue Finanzmarktstressindizes, die umfassender sind und einen stärkeren Fokus auf den Bankensektor legen. Zweitens setzen wir ein nicht-lineares VSTAR Modell ein, das bisher nicht verwendet worden ist. Wir erwarten, dass dieses Modell besser geeignet ist, die Beziehung zwischen der ökonomischen Aktivität und dem Finanzmarktsektor zu modellieren, da es glatte Regimewechsel ermöglicht. Drittens untersuchen wir umfassend die (potentiell wechselnden) dynamischen Zusammenhänge zwischen dem Finanzsektor und der Realwirtschaft im Zeitverlauf.

In den meisten Euro-Ländern führt ein Schock in dem Finanzmarktsektor zu einer langanhaltend negativen Reaktion der wirtschaftlichen Aktivität, die regime-abhängig ist. Dennoch ist die negative Reaktion nicht so stark ausgeprägt wie in anderen Studien. Dies kann daran liegen, dass der Regimeübergang eher glatt als abrupt modelliert wird. Schocks können daher gedämpft werden, so dass der negative Effekt auf die ökonomische Aktivität schwächer ist. Zweitens hängen die Ergebnisse stark davon ab, welcher Zeitraum zugrunde gelegt wird. Wir zeigen, dass die dynamischen Zusammenhänge zwischen dem Finanzmarkt und der wirtschaftlichen Entwicklung im Laufe der Zeit variieren. Linearität kann für einige Euro-Länder über gewisse Zeitperioden nicht abgelehnt werden, sodass Nicht-Linearitäten als permanentes Element in Frage gestellt werden. Unsere Ergebnisse deuten aber auf eine zunehmende Bedeutung von Nicht-Linearitäten mit dem Ausbruch der Finanzkrise hin. Selbst wenn Linearität abgelehnt wird, ist der typische negative Output-Effekt nicht immer vorhanden. Das gilt insbesondere für den Zeitraum vor der 
Lehman-Pleite, obwohl wir uns hier in einem vom Modell definierten Regime mit hohen Grad an Finanzmarktstress befinden. Dies deutet darauf hin, dass Ereignisse, die zu einem starken wirtschaftlichen Zusammenbruch führen, eher einem Finanzmarkt-Zyklus zuzuschreiben sind, der eine niedrige Frequenz aufweist und diese daher selten auftreten. 


\title{
Financial Sector-Output Dynamics in the Euro Area: Non-linearities Reconsidered*
}

\author{
Frauke Schleer ${ }^{\dagger}$ and Willi Semmler ${ }^{\ddagger}$
}

September 10, 2013

\begin{abstract}
We analyze the feedback mechanisms between economic downturns and financial stress for euro area countries. Our study employs newly constructed financial condition indices that incorporate extensively banking variables. We apply a nonlinear Vector Smooth Transition Autoregressive (VSTAR) model for investigating instabilities in the financial sector-output linkages. The VSTAR model appears appropriate since it allows for smooth regime changes and asymmetric dynamics. We find that regime-switching takes place rather smoothly which dampens the negative output response after a shock in the financial sector in the selected euro area countries. Moreover, linearity cannot be rejected for all countries over some extensive time period questioning non-linearities in the financial sector-output nexus as unambiguous feature. In particular, we show that the negative effect of financial stress on output typically observed is not always present. This holds specifically for the time before the Lehman collapse, even if this is a model-defined high stress regime. After the collapse, we observe strong amplification mechanisms. This suggests that events leading to a strong economic breakdown are rare but large events and related to financial cycles which exhibit low frequency.
\end{abstract}

JEL classification: E2, E44, G01

Keywords: Vector STAR, financial stress, financial cycle, real economy, regimeswitching, euro area

\footnotetext{
${ }^{*}$ Research for this paper has been supported by the SEEK Research Programme of the Centre for European Economic Research (ZEW). For further information on projects of the authors see www.zew. de/staff_fsl as well as the ZEW annual report on www.zew.de/en. We are especially indebted to our SEEK partners of the project "Financial Stress and Economic Dynamics: Asymmetries Within and Across euro area Countries": Peter Winker and Timo Teräsvirta. We thank them for extensive comments on this paper. We thank Patrick Vosskamp, Leonhard Brinster, Seong Hyun Hwang and Daniel Maas for excellent research assistance. We are also grateful to Marcus Kappler.

${ }^{\dagger}$ Centre for European Economic Research (ZEW), P.O. Box 103443, D-68034 Mannheim, Germany, Phone: +49/621/1235-164, Fax: +49/621/1235-223, E-mail: schleer@zew.de

${ }^{\ddagger}$ Henry Arnhold Professors of Economics, New School for Social Research, 79 Fifth Ave., New York, NY 10003, USA, and ZEW Research Associate, E-mail: semmlerw@newschool.edu
} 


\section{Introduction}

The financial and economic crisis has stressed the need for a better understanding of destabilizing effects, in particular arising from the financial sector, and how these may spill over to economic activity. In turn, weakening economic conditions are likely to feed back to the financial sector, giving rise to a so-called adverse feedback loop.

Recent studies incorporate financial market frictions into theoretical models or analyze the spill-over mechanisms from the financial sector to the real economy. Non-standard amplification mechanisms such as the credit channel or financial stress to economic activity have recently started to become more important in theoretical modeling. Beside the financial accelerator theory of the work by Bernanke et al. (1999), in the past mostly applied to firms, there is a more recent literature concentrating on the banking sector as a source for business cycle dynamics. Such theoretical studies have started with Stiglitz and Greenwald (2003) and continued with Adrian and Shin (2009), Adrian et al. (2010), Geanakoplos and Farmer (2009), Gorton (2010), Geanakoplos (2011), Brunnermeier and Sannikov (2013), and Mittnik and Semmler (2013). For instance, the latter build on the balance sheets of banks showing that there is a downward spiral through overleveraging, financial linkages and contagion. Those theoretical models have in common that i) they underline a critical impact of financial sector dynamics on economic activity and ii) they highlight non-linear amplification and destabilizing effects.

Mittnik and Semmler (2013) as well as Brunnermeier and Sannikov (2013) emphasize that a theoretical analysis based on traditional log-linearization techniques is likely to be inadequate due to local instabilities, and non-linear amplification mechanisms which do not arise near the steady state but can generate globally multiple regimes. Their theoretical models and simulation results are in contrast to the DSGE model tradition where amplifying effects occur locally around a stable unique steady state. In our paper, a model that allows for regime switching between low and high financial stress is introduced. This will motivate our empirical work employing a VSTAR regime switching model.

As to empirical work, there is a growing econometric research that also deals with the impact of financial stress on economic activity. Extensions are now made to multivariate systems since those are able to capture this kind of interdependent dynamics. The more recent research strand also accounts for non-linear dynamics (see Hubrich et al. (2013), Holló et al. (2012), Mittnik and Semmler (2013), Hubrich and Tetlow (2012), and Davig and Hakkio (2010)). The results of these studies indicate that financial stress has a strong, but regime-specific impact on the real economy. In particular, all studies find extreme negative effects of an increase of financial stress on economic activity in a distressed period, whereas the effects in a low stress period are relatively small or even negligible. Besides the stronger effect, Hubrich and Tetlow (2012) point out that the negative impact on the economy is longer-lasting in high stress periods. The model outcomes of Mittnik and Semmler (2013) imply additionally that the size and sign of shocks may matter. The 
need for applying non-linear models to the financial-sector output nexus is also stressed by Hubrich and Teräsvirta (2013).

Yet, so far lacking is work on non-linear linkages and asymmetric dynamics as they may unfold over time. For instance, the magnitude to which financial sector instabilities affect economic activity could depend on the actual state of the financial sector which is more severe at some downswings than others. Thus, non-linearities might not matter much for a long time period but then may generate a rare and large event.

In our empirical work we analyze the feedback mechanisms between economic downturns and financial stress as they may appear at some time periods. Based on a new, broader data set for extracting financial condition indices, that extensively includes banking variables, we explore the financial-real nexus and how it behaves over time. We also study the existence of heterogeneity across the euro area countries.

The hitherto theoretical and empirical findings suggest the need for an empirical approach that can accommodate varying dynamic patterns across alternative states of the economy. We propose a non-linear multivariate Vector Smooth Transition Autoregressive (VSTAR) model framework, developed by Teräsvirta and Yang (2013a)b), which has not been used empirically so far. In contrast to previous studies it is able to capture smooth regime changes. We expect the transition from one to another regime in the financial market-output nexus to be rather smooth. Misleading results may be produced by abruptly changing regime-models. Our contribution is threefold: first, we use financial condition indices which are more comprehensive and put a stronger focus on the banking sector. Second, we apply a non-linear VSTAR model which has not been used before. We think it is more appropriate to model the relationship between output and the financial sector since it allows for smooth regime changes. Third, we comprehensively investigate the (potentially changing) dynamics between the financial sector and the real economy over time for selected euro area countries.

We confirm the relevance of non-linearities in the financial sector-output nexus by using a Vector STAR model. In most countries, a shock to the financial market leads to a long-lasting negative response in economic activity which is regime-dependent. Yet, the negative effect is not as pronounced as it is in some other studies. This may be the result from, first, regime changes taking place rather smoothly than abruptly which may dampen the negative outcome. Second, the results centrally hinge on the time periods studied. We show that dynamics in the financial market-macroeconomy linkage vary over time in the euro area countries. The typically found negative output effect is not always present, particularly before the Lehman collapse, although we are in a model-defined high stress regime. This suggests that events leading to a strong economic breakdown are rare and related to a financial cycle with low frequency.

The paper is organized as follows. Section 2 motivates our empirical analysis by a theoretical model which allows for (smooth) regime-switching between a low and high 
stress regime. Section 3 derives empirical results of the financial sector-output relation. Section 3.1 describes the constructed ZEW Financial Condition Indexes (FCI). The nonlinear VSTAR model and its characteristics are considered in section 3.2. In section 3.3, we first contrast results of linear and non-linear models. Second, we analyze the financial market-output nexus over time. Finally, section 4 concludes.

\section{Theoretical Model}

Next, we introduce a financial - real interaction model with an essential role of the financial sector. The model introduced here resembles Brunnermeier and Sannikov (2013) and represents an extension of the model by Mittnik and Semmler (2013). Both models focus on the balance sheets of the banking system, whereas the former authors stress the volatility of asset prices and contagion effects to generate destabilizing feedback loops, the latter study's feedback loops arise from leveraging, financial linkages and sudden jumps in credit spreads. A similar line of research, is proposed by Stein $(2012)$ where overleveraging of the banking sector, as compared to optimal leveraging, is made central and can trigger a high stress regime.

In this type of research model typically, when leveraging and payouts are less constrained, and financial stress and risk premia are high the banking system is vulnerable and more prone to a regime of high financial stress and instability. With stronger decision restrictions on leveraging, low interest rates and low credit spreads a regime of less financial stress, stability of the banking system and a good macro performance might emerge. Yet, as Stein (2012) points out this is likely to be also a period - because of the low interest rate, low credit spread, rising capital gains and higher leveraging - that gives rise to the vulnerability of the banking sector, creating the conditions for a fragile future banking - macro link. Thus, those financial sector - macro feedback loops can create a regime of low financial stress, stable environment and expansionary periods, but are also likely to generate destabilizing forces generating contractions and recessions. This might occasionally occur when the financial sector starts to come under stress, risk premia rise and capital gains, due to a collapse of asset prices, rapidly fall making themselves felt on aggregate demand and output.

Empirically there have been by now numerous extensive studies on those vulnerable regimes and destabilizing feedback loops 1 Many studies have called this a vicious cycle $2^{2}$ What, however, recently has been explored is a "diabolic loop". This has particularly become very relevant in Europe where the financial crisis 2008/9 was quickly followed by a sovereign debt crisis. Then, there is not only the relationship of banks with the private sector, but there is a triangle relationship between private borrowing, bank leveraging, and

\footnotetext{
${ }^{1}$ See for example, Stein (2012) and Mittnik and Semmler (2013).

${ }^{2}$ See Brunnermeier and Sannikov (2013), Geanakoplos (2011), Stein (2012), Mittnik and Semmler (2013).
} 
sovereign debt, see Brunnermeier and Oehmke (2012). Banks give not only loans to the private sector, but also keep treasury bonds on their asset side. Banks vulnerability can arise due to a threat of private loan losses or an asset price fall, or due to the deterioration of the fiscal position of the sovereign. When the banks are threatened by insolvency, and a bank bail out by the public occurs, sovereign debt as well as sovereign insolvency threat rises, which make the banks even more vulnerable, cutting their loan supply to the private sector, which in turn generates less revenue for the state with greater threat of insolvency risk and so on. Moreover, both the private sector as well as public sector borrowing are usually accompanied by an increase in external liabilities, see Stein (2012: ch.8).

In our modeling strategy we want to refer to two strands of literature. First, we build on the literature about those complex feedback loops which can create vulnerable regimes. This is best understood in a multi-period model where one allows for leveraging of economic agents and asset price movements. There are several reasons why the choice of a multi-period model is insightful:

- One needs to track the path of dynamic variables over a longer horizon. The evolution of debt and the sustainability of debt can only be tracked over a longer horizon, though we do not assume an infinite horizon here.

- Leveraging and the evolution of debt is frequently seen to be interconnected with asset prices and net worth (see Geanakoplos (2011), and Stein (2012)). To have a multi-period payoff function either for consumers, banks or firms, is essential in asset pricing theory.

- The outcomes of such an intertemporal decision model with finite horizon can then be compared to standard macro models with infinite horizon. One also can easily evaluate policy effects in this context.

Second, we also want to take into account amplification and feedback loops that are mentioned as essential, for example in Brunnermeier and Sannikov (2013), Mittnik and Semmler (2013) and Stein (2012). Macroeconomics amplification mechanisms have been known since long but they are rare in DSGE models, since mean reversion is usually assumed. The following magnifying effects could be at work in certain regimes, possibly triggering a regime switch:

- On the real side there could be a strong multiplier effects in certain regimes, generating stronger feedback loops, for example if multipliers turn out to be stronger in recessions than in expansions (Mittnik and Semmler 2012).

- Interest rates and credit spreads could also be regime dependent (and different from the interest rate that results from the Taylor rule), moving counter-cyclically, as often described by the literature on the financial accelerator. 
- The Fisher debt deflation effect might become relevant, for example triggering a rise of the fraction of households deleveraging, see also Eggertsson and Krugman (2012) $3^{3}$

- There could be price expectation and real interest rate effects that are destabilizing, for example deflationary pressures, pointed out by Tobin (1975)'s work.

- There are wage channel effects that can trigger amplifying forces (this depends of course on the shape of the Phillips curve) $4^{4}$

- The asset price channel could also be amplifying, through wealth effects on aggregate demand (for example amplifying an upswing with asset prices rising, but also accelerating a downswing in periods of large asset price losses).

- There could be banking vulnerability due to overleveraging, loan losses and asset price fall, with externality and contagion effects, which could trigger the above mentioned "diabolic loop".

Brunnermeier and Oehmke (2012, p.30) in particular stress the importance of amplifying mechanisms arising from externalities and contagion effects. They write why does a shock "...propagate across so many sectors of the economy? The reason is amplification. In the presence of amplification, even a modest triggering event can cause large spillovers across the financial system. Amplification can occur because of direct spillovers, such as socalled domino effects, or indirect spillovers that work through prices, constraints, and the endogenous responses of market participants."

Though the proposed model could be more explicitly related to the work by Stein $(\overline{2012})$ we only sketch some important amplification mechanisms. In the US and also in Spain, so Stein's view, the sectors with asset price boom, such as financial intermediaries and real sectors, have helped to service the debt from high capital gains. On the other hand, the high leveraging and over-borrowing might trigger high risk premia, high interest rates and credit spreads and collapse of financial linkages. This is then likely to be accompanied by a fall in asset prices and stronger losses in capital value and net worth, finally generating, through macro feedback loops, an economic contraction.

This dynamic process can easily generate a regime switch from low to high financial stress and banking instability entailing an economic recession $5^{5}$ Furthermore, one might want to understand the above sketched adverse feedback loops by dealing with an open economy. This can be done by following an approach suggested by Blanchard and Fischer (1989). For recent empirical evidence of the relevance of external debt on the macrodynamics in

\footnotetext{
${ }^{3}$ They extensively treat the Fisher debt deflation effect in their paper, but they also stress the households' deleveraging effect on demand.

${ }^{4}$ See Charpe et al. (2013).

${ }^{5} \mathrm{~A}$ similar model of asset price credit market boom is also presented in Semmler and Bernard (2012).
} 
Europe, see Stein (2012; ch.8). This as well as the central bank's policy responses will be taken into account in our model.

Most of the recent dynamic models, such as DSGE models and the Brunnermeier and Sannikov (2013) and Mittnik and Semmler (2013) models, as well as Blanchard and Fischer (1989), are working with an infinite horizon model. In our context, as we will show, an infinite horizon model is not needed. We here propose to solve the model with a receding finite horizon by a new numerical procedure, the NMPC method, see Grüne et al. (2013), summarized in the Appendix A. This is a new solution procedure that allows for a multi-period model, but also better includes some of the above discussed macroeconomic feedback loops and amplification mechanisms. Yet, it approaches, with longer horizon, the usual infinite horizon solution.

\subsection{Regime of Low Financial Stress}

In a first model variant we presume that the interest rate on borrowing is at a low level and remains constant. This can be seen as equivalent to the case of the central bank pursuing a low - or near zero - interest rate policy. By this policy, the central bank is aiming to keep the economy in a low financial stress regime ${ }^{6}$ The detailed measure of financial stress that also includes banking as well as sovereign risk variables, will be discussed in the next section. Our model variant for the low stress regime reads as follows:

$$
V(k, d)=\max _{c_{t}, g_{t,}} \int_{0}^{T} e^{-r t} U\left(c_{t}\right) d t
$$

s.t.

$$
\begin{gathered}
d k_{t}=\left(g_{t}-\delta\right) k_{t} d t+\sigma_{t} k_{t} d Z_{t} \\
d b_{t}=\left(r b_{t}-\left(y_{t}-c_{t}-i_{t}-\varphi\left(g_{t} k_{t}\right)\right)\right) d t
\end{gathered}
$$

In equ. (1) there are preferences over log utility. The policy variables in equ. (1) are consumption $\left(c_{t}\right)$, and growth rate of capital stock $\left.\left(g_{t}\right)\right]^{7}$ The horizon $T$ does not have to be very large, or go to infinity $\left.\right|^{8}$

Equ. (2) represents the capital stock. It increases due to investment but declines due to a capital depreciation rate $\delta$. Brunnermeier and Sannikov (2013) have a stochastic shock in a Brownian motion and volatility dependent asset prices. We can also admit

\footnotetext{
${ }^{6}$ See Christiano et al. (2011), and Woodford (2011).

${ }^{7}$ Actually in the numerics we can take $\tilde{c}=c / k$, and then multiply it by $k$ in the preferences, so that the first two choice variables can be confined to lie between 0 and 1 .

${ }^{8}$ For details of such a model with short time horizon, approximating well models with longer time horizons but needing much less information, see Grüne et al. (2013). Those type of models are called Nonlinear Model Predictive Control, see Grüne and Pannek (2011), where the basic theory is developed without discounting.
} 
stochastic shocks occurring along the path, represented by the second term in equ. (2). This is the only stochastic shock we may built in (though we will neglect it in our current version when we solve the model). Equ. (3) represents the dynamics of aggregate debt (households and firms) 9 . Our debt dynamics are written here in a way which is standard if one allows for borrowing of households, firms and the sovereign. As mentioned we also allow here for external debt 10

The interest payment on debt, $r b_{t}$, increases debt but the surplus $\left(y_{t}-c_{t}-i_{t}-\varphi\left(g_{t} k_{t}\right)\right)$ - the excess of income over spending - decreases debt through a surplus 11 Hereby we have $i=g_{t} k_{t}$. Note that consumption and investment are separate decision variables. Moreover, $\varphi\left(g_{t} k_{t}\right)$ is the adjustment cost for investment. Overall the model has two decision variables and two state variables. Note also that we have quadratic adjustment cost of investment and we could permit a difference of interest and discount rates ${ }^{12}$

One can allow the income $y$ to be split up into $y=$ normal return on capital + capital gains + wage income ${ }^{13}$ Then the excess return on capital income over the interest rate, generated through capital gains, can be used to service the debt, see Stein (2011).

Now we solve our above model by using NMPC. ${ }^{14}$ Assuming here $r=0.04, \delta=0.07$ and quadratic adjustment cost of investment, we obtain the following solutions using NMPC, yet, setting the shock in equ. (2) equal to zero.

For a regime of low financial stress, in figure 1 the vertical axis shows the debt to capital stock ratio, the horizontal is the capital stock. Here the paths are shown for different initial conditions. The upper end of the two paths represents the steady state which is unique where both the trajectories end up. The NMPC numerics guarantees that the transversality condition holds - the trajectories are not explosive but converge toward a steady state where the left hand side of equ. (3) is zero. So, with the central bank keeping the interest rate low there is a regime of low financial stress where debt is sustainable ${ }^{15}$ Figure 1 gives the solution paths for two different initial conditions, but the same discount and interest rates. We could also assume that the central bank is able to reduce the discount rate and interest rates through appropriate monetary instruments even to a lower rate. The results of the NMPC solution for example, with a temporarily different

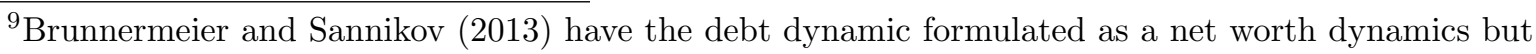
a closed economy framework. In our open economy framework, we could also allow for sovereign debt here.

${ }^{10}$ In fact borrowing can be interpreted as borrowing taking place also from abroad, see Blanchard and Fischer (1989).

${ }^{11}$ How this works for an open economy, and what the stylized facts for Europe are can be found in Stein (2012; ch.8).

${ }^{12}$ This is frequently done in a two type of agent model, as Eggertsson and Krugman (2012).

${ }^{13}$ Note that the capital gains could be positive or negative, for a more detailed specification of those, see Stein (2012).

${ }^{14}$ See the sketch of the algorithm in the Appendix A

${ }^{15}$ This is consistent with the case put forward by Bohn $(2007)$ that the debt is mean reverting when the reaction coefficient (the response of the surplus with respect to sovereign debt) in his debt dynamics is greater than the interest rate. In his case however the interest rate is a constant, or only slightly varying through the growth rate of marginal utilities, if he takes the latter to determine the discount rate.
} 


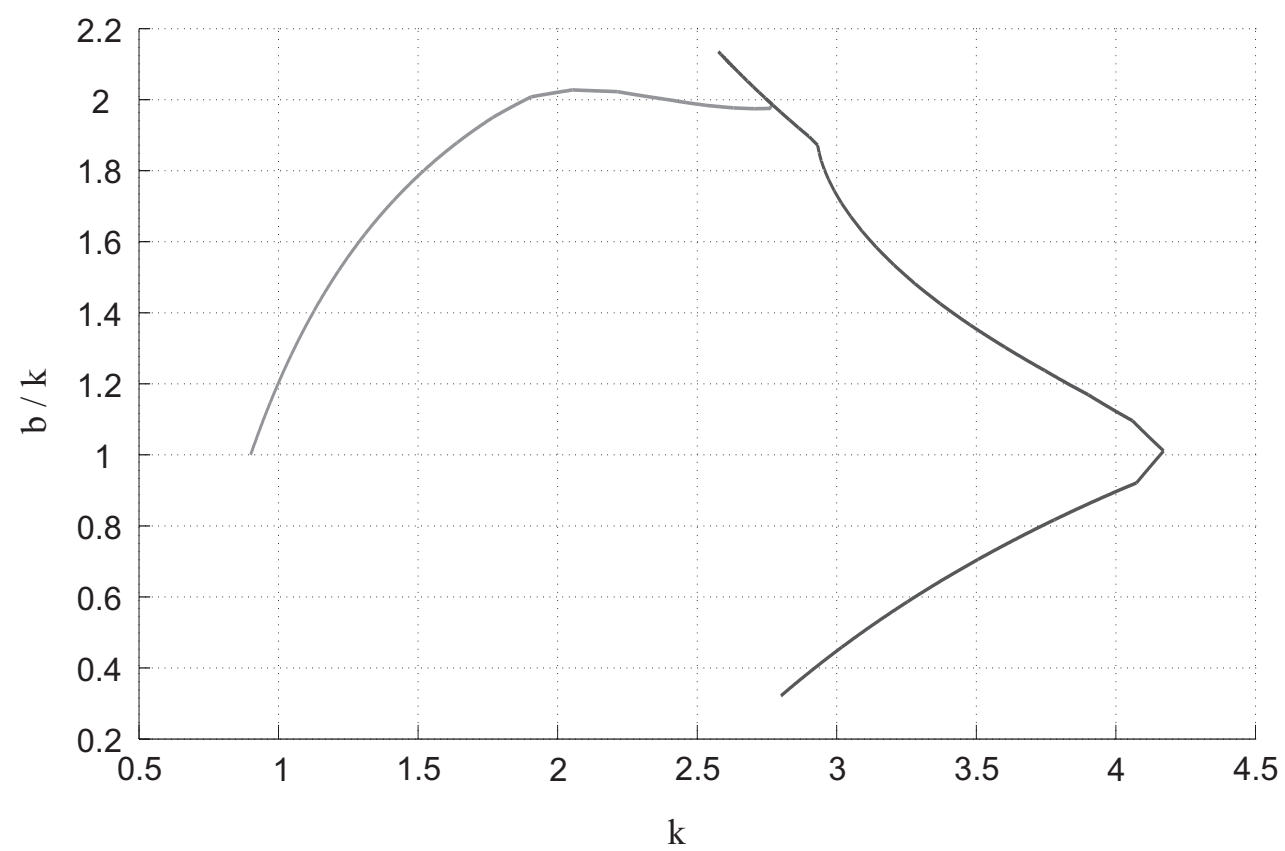

Figure 1: dynamic paths of sovereign debt for constant interest rate, for two initial conditions, $k(0)=0.9, b(0)=0.9$ (left) $k(0)=2.8, b(0)=0.9$ (right, bold), convergence to steady state, with $r=0.04$.

interest rate, or credit spread, can also easily be obtained. Results from our solution method have shown that the solution paths converge toward the steady state, yet for a smaller interest rate there is a lower debt to output ratio on the out of steady state path.

In this first model variant we keep the interest rate on leveraging persistently low, by assuming that there is low financial stress and the central bank can sufficiently reduce not only the interest rate but also credit spreads by reducing financial stress. This may generate a tranquil period where there are large capital gains and an asset price boom, where risk premia are low and asset prices rising. Yet, when an overleveraging occurs and the asset price bubble bursts and capital gains become negative, then net worth maybe rapidly deteriorating. As the debt ratio rises and the capital gains fall, and interest rates and credit spreads are likely to rise - the latter being negatively correlated with the capital gains - net worth of the assets can quickly vanish or become negative ${ }^{16}$ Regime dependent interest rates and credit spreads are discussed next.

\section{$2.2 \quad$ Regime of High Financial Stress}

We next allow the yields on bonds, sovereign or private, and financial stress, to be endogenous. This presumably will then also entail endogenous feedback loops of the financial stress to macroeconomic variables, possibly giving rise to the loss of stability. This is somewhat equivalent to the central bank not attempting - or not being able - to pursue a monetary policy to reduce asset market stress and to bring down credit spreads. Let

\footnotetext{
${ }^{16}$ For details of such a scenario, see Stein $(2012)$.
} 
our model now be defined as follows

$$
V(k, d)=\max _{c_{t}, g_{t},} \int_{0}^{T} e^{-r t} U\left(c_{t}\right) d t
$$

s.t.

$$
\begin{gathered}
d k_{t}=\left(g_{t}-\delta\right) k_{t} d t+\sigma_{t} k_{t} d Z_{t} \\
\left.d b_{t}=r\left(s_{t} \mid \gamma, c^{*}\right) b_{t}-\left(y_{t}^{a}-c_{t}-i_{t}-\varphi\left(g_{t} k_{t}\right)\right)\right) d t
\end{gathered}
$$

The difference to the model of low stress regime is here now that we assume state depending financial stress, represented by the banking sector, security and exchange rate market variables. Following the line of much other research, we make now interest rate to be paid on debt a non-linear function of some state variable. Since we want to have the function to be bounded we can define financial stress to be given by the following function:17

$$
r\left(s_{t} \mid \gamma, c^{*}\right)=\left[1+\exp \left(-\gamma\left(s_{t}-c^{*}\right)\right)\right]^{-1}, \gamma>0, c^{*}>0
$$

This function makes the credit cost depending on the state variable financial stress, $s_{t}$, a threshold variable, $c^{*}$, and a slope parameter, $\gamma$. The above represents the logistic function often used in STAR models and further discussed in our specification of the VSTAR model in sect. 3.2 below. It is also roughly the function that has been empirically observed in De Grauwe (2012) ${ }^{18}$ but one can also derive from Roch and Uhlig (2012). ${ }^{19}$ In our numerical solution procedure we will approximate this function above by a closely related function 20

Now if we were to look at the asset side of the economy, asset prices are likely to fall or do not grow any more and capital gains could become negative. So if the capital gains shrink, the source for debt services declines, and surpluses would shrink, the debt service rise with higher interest rates and debt sustainability becomes threatened 21

Note also that when we allow the income $y^{a}$ in (6) to include capital gains, aiding to

\footnotetext{
${ }^{17}$ Note that empirically we will introduce a multitude of factors generating financial stress. For the shape of the function in equ. (7) see Figure 4.

${ }^{18}$ Presenting there EU debt and bond yield data, see also Corsetti et al. (2013).

${ }^{19}$ In DSGE models the rise of risk premia and its persistence on a high level is often modeled through large shocks with some strong persistent, see Gilchrist and Zakrajšek (2012).

${ }^{20}$ Since in our numerics we cannot directly read in the financial stress, $s_{t}$, we approximate (7) by an arctan function such as $r\left(b_{t} / k_{t}\right)=\beta \arctan \left(b_{t} / k_{t}\right)$, We hereby have set $\beta=0.1$. Here too, the credit cost rises in a non-linear way with the debt to capital stock ratio, first slowly, then more rapidly but is finally bounded. Yet, this function behaves the same way as the above logistic function, except that it is a bit flatter at its upper and lower branches. Also, the arctan function is not bounded by 1 and 0 but can move in reasonable bounds as needed to approximate actual credit cost. It is also numerically easier to solve in our NMPC algorithm.

${ }^{21}$ For a scenario like this, see Stein $(2012)$ where this is exemplified with macroeconomic data for Spain and Ireland.
} 
service the debt, there is an advantage for borrowing agents as long as there is little financial stress and no risk premium to be paid. We want to remark that low interest rates and capital gains are frequently highly (negatively) correlated. This points to a kind of low frequency financial cycle scenari ${ }^{22}$ where financial stress and financial fragility may arise in a period of tranquility where low stress and zero risk premia can be observed, as for example were seen from the 1990s to 2007. Implicitly, in this case, on the asset side, as Stein (2012) shows, the present value of the assets will tend to become very large, because there is no correction through risk premia. ${ }^{23}$ as it should be, and net worth will be high.

The reversal of this process is likely to trigger macroeconomic instabilities when financial stress is significantly driven by asset prices and banking vulnerability. Note that asset prices are likely to fall with higher interest rates, rising risk premia and credit spreads, and higher discount rates ${ }^{24}$ Asset prices falling means capital losses. Yet, sudden loss of capital gains generate lower income to service debt, at a time when debt service rises through rising financial stress and credit spreads. The asset price bubble may burst in a period when high debt services emerge. ${ }^{25}$ There are now endogenous risk premia, rise of interest rates and prices of asset declining.

This triggers important macroeconomic feedback loops that one often can be observed during periods of rising financial stress, as for example listed above. This is frequently accompanied by a decline in aggregate demand and output. 26 Though optimal consumption and investment plans might be targeted, actual income, consumption and investment are likely to decline due to rising financial stress — falling asset prices, rising risk premia and credit spreads. So, overall we may experience that actual output adjusts downward:

$$
y_{t}^{a}=g\left(r\left(s_{t} \mid \gamma, c^{*}\right)\right)\left(i^{o p t}+c^{o p t}\right)
$$

Note that in equ. (8) we have now defined actual output to be driven by aggregate demand, where consumption and investment demand, responding to financial stress are affecting actual output. The optimally chosen consumption and investment demand for each time period of the state variables are actually not realized, but only the consumption and investment demand under the impact of financial stress are executed. This can easily be executed by our NMPC algorithm. What is modeled here is what Blanchard and Leigh (2013) call the feedback of financial market stress on aggregate demand ${ }^{27}$

\footnotetext{
${ }^{22}$ Financial cycles as rather long cycles are studied in Schularick and Taylor (2012).

23 Stein (2012) suggests then to make corrections by suggesting to take the trends/drifts in capital gains and interest rates in such a model, that would better measure some debt capacity. The borrowing exceeding that debt capacity would amount to excess borrowing.

${ }^{24}$ See Semmler and Chen (2013).

${ }^{25}$ See Stein (2012).

${ }^{26}$ See Blanchard and Leigh (2013), and Corsetti et al. (2013). The latter show how empirically sovereign debt and banking risk also increases private borrowing cost.

${ }^{27}$ This is what a recent IMF study defines as follows: "The risk channel amplifies the transmission of shocks to aggregate demand, unless monetary policy manages to offset the spillover from sovereign
} 
We can note that if risk premia and credit spreads and thus financial stress rise, but are bounded as in (7), $y_{t}^{a}$ will decline due lower consumption and investment demand, but if demand and output falls, income, and thus tax revenue, as well as capital gains, and the surplus, to service the debt, are likely to fall, too. This might make then debt and bond issuing - if bonds are sold on the market - unsustainable, because of further jumps in financial risk.

Next we solve our model (4) - (8) numerically using again NMPC. We illustrate the outcome by two variants. In both variants we are in a regime of high financial stress. First, we are setting the macro feedback loops on aggregate demand, $g\left(r\left(s_{t} \mid \gamma, c^{*}\right)\right)$, to be very weak. We get the following results.

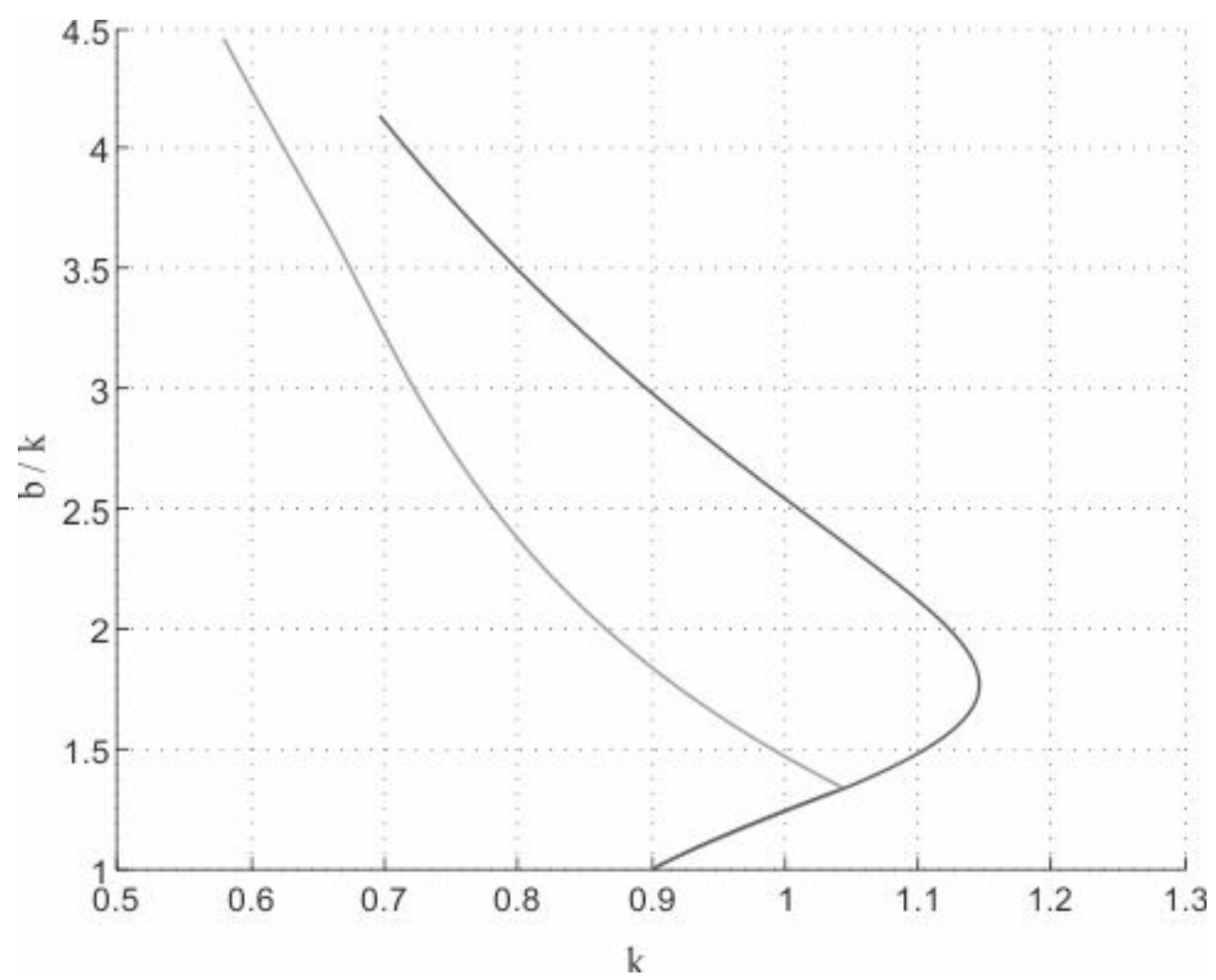

Figure 2: Debt dynamics for non-linear financial stress effects; weak effects on aggregate demand (right graph, bold); strong effect on aggregate demand (left graph), for initial conditions $k(0)=0.9, b(0)=0.9$

As the solution path for the capital stock and leveraging in figure2 (right graph) shows the credit spread below a certain threshold permits a higher capital stock and higher leveraging. Yet as the credit spread rises - in our case caused by financial market stress - and if it reaches a certain threshold, we observe that with an increasing leveraging risk premia rise, capital stock stops rising but the leverage ratio is rising further. Thus, if the credit spread is moving beyond a certain threshold, debt becomes unsustainable since capital gains fall and the interest payments become higher than the surplus to service the default risk to private funding costs", Corsetti et al. $(2013)$. 
debt, see (6) 28

Stronger macroeconomic feedback loop ${ }^{29}$ may arise due to the following:

- There is the wealth effect reducing aggregate demand - when the capital appreciation falls, or becomes negative, both consumption and investment demand are likely to fall.

- The share of households that are income and credit constrained, in the sense of Galí et al. (2007), and households that are higher leveraged and are under financial stress $\sqrt{30}$ are significantly rising in a contraction period of the business cycle, see also Mittnik and Semmler $(2013 ;$ 2012).

- As the financial market forces trigger banking and financial stress ${ }^{31}$ the central bank may have no instruments available - or is not willing - to force the interest rate down further and/or to reduce risk premia and credit spreads, for example by purchasing bad assets and bonds to drive down asset market risk and risk premia. 32

- The fraction of private households start strongly deleveraging that reduces income and liquidity of other households and firms, which might be accompanied by a Fisher debt deflation process, see Eggertsson and Krugman (2012) ${ }^{33}$

- Finally, there could occur even a worse feedback: a weak financial sector, holding risky sovereign or other debt, may come under severe stress, because debt may go into default and banks reduce lending to the real economy, or worse, may even default 34

Whereas the first four destabilizing mechanisms have been known in the literature and are often viewed to generate a vicious cycle, the last one, which has recently been discussed, adds a more dangerous mechanism which has been, as mentioned, called "diabolic loop" 35

\footnotetext{
${ }^{28}$ This maybe be magnified by the reversion of the effect as mentioned before: namely the risk and risk premia rising, discount rates rising and falling (or negative) capital gains, not supporting the debt repayments any more. So debt would rise faster.

${ }^{29}$ A systematic study of macroeconomic feedback effect, know from the history of macroeconomics, partly stabilizing partly destabilizing, are extensively discussed in Charpe et al. (2013).

${ }^{30}$ The share of those households matter, since there is empirical evidence that the drop in demand will be larger for households with larger debt, that are forced to deleverage more, see Eggertsson and Krugman (2012).

${ }^{31}$ See the ZEW financial condition index.

${ }^{32}$ The ECB in Europe was for example constrained by the Maastricht Treaty not to purchase sovereign bonds. Later this was relaxed by allowing it to purchase sovereign bonds on the secondary market, though there a number of programs that by-passed the Maastricht Treaty.

${ }^{33} \mathrm{~A}$ detailed discussion of further macroeconomic feedback effects of this type can be found in Charpe et al. (2013).

${ }^{34}$ See Brunnermeier and Oehmke (2012), and Bolton and Jeanne (2011), the latter present data on the sovereign debt holdings of banks.

${ }^{35}$ See figure 5 in Brunnermeier and Oehmke (2012) and see also Bolton and Jeanne (2011).
} 
Now we expect, starting with a debt to capital stock ratio roughly above normal that the above feedback mechanisms lead to higher financial market stress and higher risk yields, higher credit spreads and lower output, leading to a contraction in the utilization of the capital stock, and capital stock itself, and to an increasing debt to capital stock ratio 36

The debt dynamics with endogenous credit spread and endogenous demand and output contraction of system (4) - (8) are shown in figure 2 (left graph), using again the NMPC solution method. The situation is sketched here also assumes that the central bank cannot - or is not authorized to - bring down the financial market stress through financial market interventions.

Figure 2 (left graph) shows, starting with a debt to capital stock ratio of roughly unity, the feedback mechanisms of higher financial market stress - higher risk premia, higher yields and higher credit spreads - and lower output leading to a contraction of capital stock and increasing debt to capital stock ratio.37

Given those above sketched macro feedback loops and a lack of a proper central bank's reaction it is easily explained why there might be a regime switch from a low to a high stress regime where vulnerabilities increase and a faster deterioration of demand and output as well as unsustainable debt dynamics are likely to occur, as shown in the two graphs in Figure 2.

\section{Empirics}

In the following, we present our empirical strategy and the results derived. In section 3.1. we present the ZEW Financial Condition Indices for selected euro area countries which are used to model the financial sector conditions or stress levels. Next, we introduce the Vector STAR model in section 3.2 as well as our empirical modeling cycle and evaluation strategy of the financial market-output relation. Section 3.3 discusses, first, linear vs. non-linear model outcomes. Second, we analyze the financial sector-output link and its amplification mechanisms over time.

\subsection{Financial Condition Indices for selected euro area countries}

In this section, we briefly describe the $Z E W$ Financial Condition Indices (FCI) for the euro area. Kliesen et al. (2012; p.372) state that there is a a high degree of overlap between financial stress and condition indices (FSI vs. FCI). They point out that stress indices contain more price variables, whereas condition indices are broader including also quantities. "As such, an FSI can be considered a snapshot of the level of fragility in

\footnotetext{
${ }^{36}$ This could equivalently create a downward spiral in net worth, if the model is written in terms of net worth, as Brunnermeier and Sannikov (2013) and Stein (2012).

${ }^{37}$ Note that a strong contractionary effect could also occur if the creditors become unwilling to lend when a certain debt to GDP ratio is reached and new borrowing or rolling over of old debt will be discontinued. For a model including such a sudden rise of credit market constraint, see Ernst and Semmler (2012).
} 
the financial market and an FCI a mapping of financial conditions onto macroeconomic condition." Nevertheless, there is no clear-cut distinction of financial stress and condition indices. The ZEW indexes are broad indexes with a fairly high negative correlation to IP growth, so they are called ZEW financial condition indexes, reflecting both vulnerability of the financial market as well as a link to the macroeconomy. In the following we will refer to financial stress and financial conditions synonymously.

The data-set used extends this of available FSI and FCI by various variables. Some of them are neglected in the existing financial stress indices but play an important role in describing financial stress as it occurred after (and to some extent before) the Lehman collapse, for instance. Many of the existing indices focus predominately on price variables, whereas our index expands also to movement in volumes, particularly within the banking sector. The financial sector and economic breakdown were closely related to the banking sector. Adding banking-related factors with a close link to the economic downturn, contribute to the improvement of a financial condition index. In particular, some of these additional factors, namely the annual growth rate of assets over liabilities, the ratio of short over long-term debt securities issued by bank ${ }^{38}$ and, the annual growth rate of lending of banking to the private sector, reflect dynamics of the theoretical model introduced in section 2 before. We emphasize that it is not sufficient to comprise only an aggregated euro area indicator. Such an index would not reflect the heterogeneity of the financial sector of the individual euro area member states adequately (see also Bijlsma and Zwart (2013)).

The FCIs are available for Belgium, Germany, Austria, Finland, France, Greec ${ }^{39}$, Ireland, Italy, Netherlands, Portugal and Spain from 1980:01 to 2013:01 on a monthly basis (for a graphical representation of the indexes see figure 11 in Appendix B). The selected Eurozone countries account for almost $98 \%$ of total euro area GDP. There do not exist Financial Stress or Conditions Indices which are as comprehensive as the ZEW FCIs in terms of their broadness of different stress categories and country coverage. The ZEW FCIs consist of three (standard) categories: banking sector, security market and foreign exchange market. The following variables represent the banking sector: interbank rate spread, Eonia/Euribor Spreads, TED spread, bank stock market returns, beta of the banking sector, CMAX interacted with the inverse price-book ratio, inverted term spread, ratio of short over long debt security issued, bank lending to private sector, the ratio of total assets over liabilities, excess reserves, the inverse marginal lending facility, money market spread, spread of main refinancing rate and euro area 2-year government benchmark bond yield, and write-offs. The variables related to stress in the security market are

\footnotetext{
${ }^{38}$ Following Geanakoplos (2011), we do not include the assets over equity ratio variable but use flows due to their more reasonable ability in explaining stress in balance sheets of banks. The former may deliver an unreasonable measure: equity is high in a boom leading to a decline in the ratio and vice versa in a bust.

${ }^{39}$ We do not include the inverted term spread due to its paradoxical evolution during the current financial and economic crisis, see also Neely $(2012)$.
} 
given by share price returns and their volatility, corporate debt spreads and volatility of government bond returns. Volatility of real effective exchange rates is included to reflect risk in the foreign exchange market. Most of the variables are available on country level, some are Eurozone aggregates. For a detailed description of the data see Table 12 in Appendix B.

To account for a fairly high correlation across some variables, we use a dynamic factor model to extract the common factor which we call $Z E W$ Financial Condition Index. We apply the two-step estimation approach of Doz et al. (2011) which has the ability to account for ragged edges of the data sample. The dynamic factor model looks as follows:

$$
X_{t}=\Lambda_{0}^{*} F_{t}+\xi_{t}
$$

$F_{t}$ are the common factors, $\Lambda_{0}^{*}$ is the matrix of factor loadings, $X_{t}$ is the vector of observables, and $\xi_{t}$ is the idiosyncratic component. The common factor $F_{t}$ follows a $(\mathrm{V}) \mathrm{AR}-$ process $A(L) F_{t}=u_{t}$. In the initial step, the factor loadings are estimated by principal components, whereas in the second step the Kalman filter is applied.

To model economic activity, we use monthly growth rates of industrial production indices which are in constant prices and seasonally adjusted. The data is taken from the OECD and available from 1980:01 till 2013:01.

The FCIs for the euro area countries capture the country-specific and euro area wide stress periods properly, meaning they indicate financial stress if there was a financial market turmoil. They reflect the risk associated with the financial market breakdown in 2008 as well as the sovereign debt crisis. The ZEW FCIs are negatively correlated with the monthly growth rate of industrial production in the respective country (see Table 1). We conclude that the ZEW FCIs allow us to derive valuable, new insights in the link of financial sector turmoils and economic dynamics in the euro area countries.

Table 1: Correlations of FCIs and IP

\begin{tabular}{c|ccccccccccc}
\hline \hline & AUT & BEL & FIN & FRA & GER & GRE & IRE & ITA & NLD & PRT & ESP \\
\hline corr (IP,FCI $)$ & -0.0851 & -0.0505 & -0.1271 & -0.1249 & -0.2028 & -0.0426 & -0.0438 & -0.0523 & -0.0593 & -0.0425 & -0.0286 \\
\hline
\end{tabular}

\subsection{A non-linear Vector STAR approach}

Our empirical non-linear analysis contributes to the existing literature in several ways. First, we use new financial condition indices which are more comprehensive, have a stronger focus on the banking sector and are broader in terms of country coverage. Second, we apply a Vector Smooth Transition Model as proposed by Teräsvirta (1994) and Teräsvirta and Yang (2013a) which has not been used within this literature before. The Vector STAR model is able to capture the relevant non-linear dynamics in a more sophisticated and reasonable way. Third, we put a stronger focus on assessing the financial sector-output relation and non-linearities over time. 
The Vector STAR model reflects the transmission mechanisms as described in the theoretical model. It allows for smooth or abrupt regime-switching based on an observable transition variable allowing for a straightforward economic interpretation of the different regimes and can capture asymmetric dynamics of shocks and amplification effects in low and high stress regimes. The hitherto studies, which incorporate non-linearities, apply Markov Switching or Threshold Vector Autoregressive (TVAR). We prefer a model with an observable transition variable such that we can motivate the transition variable by defining a meaningful set of regimes for a particular state of the economy or the financial market (e.g. low/high stress). This leads to the exclusion of Markov Switching models which do not easily offer a direct economic interpretation. Moreover, an abrupt switch from one regime into the other like in a TVAR modeol is not plausible in our application. Marginal and negligible changes in the transition variable can lead to extreme consequences, namely, a different regime. Yet, the transition from a high to a low stress regime may take a while. For a comprehensive survey on non-linear Vector models see Hubrich and Teräsvirta (2013).

The logistic Vector STAR model looks as follows 40 :

$$
\mathbf{y}_{\mathbf{t}}=\left\{\sum_{i=1}^{m}\left(\mathbb{G}_{\mathbf{t}}^{\mathbf{i}-\mathbf{1}}-\mathbb{G}_{\mathbf{t}}^{\mathbf{i}}\right) \mathbf{F}_{\mathbf{i}}^{\prime}\right\} \mathbf{x}_{\mathbf{t}}+\varepsilon_{\mathbf{t}}
$$

where $\mathbf{y}_{\mathbf{t}}$ is a $k \times 1$ column vector, $\mathbf{x}_{\mathbf{t}}=\left(\mathbf{y}_{\mathbf{t}-\mathbf{1}}^{\prime}, \ldots, \mathbf{y}_{\mathbf{t}-\mathbf{p}}^{\prime}, \mathbf{d}_{\mathbf{t}}^{\prime}\right)^{\prime}$, and where $\mathbf{d}_{\mathbf{t}}$ is a vector containing deterministic components. $\mathbf{F}_{\mathbf{i}}=\left(\mathbf{A}_{\mathbf{i} 1}^{\prime}, \ldots, \mathbf{A}_{\mathbf{1}}^{\prime}, \boldsymbol{\Phi}_{\mathbf{i}}^{\prime}\right)^{\prime}$ includes coefficient matrices. The error term $\varepsilon_{\mathbf{t}}$ is assumed to be independent normal with zero mean and variance-covariance matrix $\Omega$. $\mathbb{G}_{\mathbf{t}}^{\mathbf{i}}($.$) is a diagonal matrix of transition functions such that$ different transition function across regimes can be modeled:

$$
\mathbb{G}_{\mathbf{t}}^{\mathbf{i}}(.)=\operatorname{diag}\left\{\mathbf{g}\left(s_{1 i t} \mid \gamma_{i 1}, c_{i 1}\right), \ldots, \mathbf{g}\left(s_{k i t} \mid \gamma_{i k}, c_{i k}\right)\right\}
$$

for $i=1 \ldots, m-1$, where $m$ determines the number of transitions across equations and $\mathbb{G}_{\mathbf{t}}^{\mathbf{0}}=\mathbf{I}_{\mathbf{k}}, \mathbb{G}_{\mathbf{t}}^{\mathbf{m}}=\mathbf{0}$. The transition function are assumed to be of logistic type which is monotonically increasing in $s_{i j t}$ and bounded between zero and one.

$$
\mathbf{g}\left(s_{i j t} \mid \gamma_{i j}, c_{i j}\right)=\left[1+\exp \left(-\gamma_{i j}\left(s_{i j t}-c_{i j}\right)\right)\right]^{-1}, \gamma_{i j}>0
$$

The transition function depends on the transition speed $\left(\gamma_{i j}\right)$, the location parameter $\left(c_{i j}\right)$ and the transition variable $\left(s_{i j t}\right)$. Usually, a $d$-times lagged endogenous variable is used. There is also the special case where only one transition function governs the whole system, then, $\mathbb{G}_{\mathbf{t}}^{\mathbf{i}}()=.\mathbf{g}\left(s_{i j t} \mid \gamma_{i}, c_{i}\right) \mathbf{I}_{\mathbf{k}}$. The latter will be the relevant model type for our application. The slope parameter $\gamma_{i j}$ and thereby, the Vector STAR model is redefined

\footnotetext{
${ }^{40}$ The notation is taken from Teräsvirta and Yang (2013a).
} 
by

$$
\gamma_{i j}=\exp \left(\nu_{i j}\right)
$$

where $\nu_{i j}$ is the parameter to be estimated following Schleer $(2013)$. Redefining $\gamma_{i j}$ facilitates the construction of a grid because one can build an equidistant grid in the dimension of $\nu_{i j}$. The search space (grid) for $\gamma$ is then automatically dense in the beginning and less so when it becomes large which is a sensible choice for estimating the Vector STAR model. In order to make $\gamma$ a scale-free parameter, it is divided by the standard deviation of the transition variable when the parameters of the VSTAR model are estimated (Teräsvirta 2004).

We use a logistic function since it is able to capture regime-switching and the kind of asymmetries we are interested in. The effects of shocks can vary across low and high stress scenarios like they do in the macroeconomy as has been shown in the theoretical model in section 2. If the economy already is in a recession period, an increase in financial stress might have different, e.g. stronger and longer lasting, effects on the real economy than in a boom and low stress scenario due to the previously described endogenous feedback mechanisms. Destabilizing effects may set in such that we face multiple regimes that do not converge to a stable equilibrium again. Technically, the logistic function is bounded between zero and one. If $\gamma$ tends to infinity it converges to a pure threshold model and if $\gamma$ approaches zero it collapses to a linear VAR model. The location parameter $c$ defines the threshold value.

Applying a Vector STAR model has the advantage of having a fully specified modeling cycle at hand consisting of three steps: testing linearity, specifying and estimating the Vector STAR model and finally, evaluating the model ${ }^{41}$ We proceed as follows:

Unit root tests: We check stationarity of the individual FCI and IP series by applying following two tests: ERS DF-GLS and ERS point-optimal developed by Elliott et al. (1996). Those tests have better power properties and lower size distortions in comparison to the standard ADF test (Hayashi 2000; p.601). Moreover, we test the stability condition of the linear VAR model, that its reverse characteristic polynomial has no roots in and on the complex unit circle (Lütkepohl 2005: p.16). To the best of our knowledge, there do not exist unit root test derived for a Vector STAR with logistic type transition function. Hence, we stick to tests for a linear model.

Testing linearity: We apply a joint linearity test of the whole Vector STAR system as recommended by Camacho (2004), Weise (1999) and formalized by Teräsvirta and Yang (2013b). Therefore, we rely on Rao's statistic which is recommended also by the latter authors due to satisfying size properties. Thereby, we choose the respective lag of the transition variable which rejects linearity at the $5 \%$ level and the p-value is minimized. For each model, the lag length is selected by the Schwarz Information criterion (Schwarz

\footnotetext{
${ }^{41}$ Teräsvirta (1998) describes the modeling cycle for a univariate procedure and Teräsvirta and Yang (2013a b) extend it for a multivariate Vector STAR model.
} 
1978 ) and the maximum lag length is set to maxlag $=\operatorname{round}\left(12(\mathrm{~T} / 100)^{(1 / 4)}\right)$ which is the formula suggested by Schwert (1989). We rely on the full lag structure, as otherwise the power of linearity tests is harmed (see Teräsvirta (2004: p. 225)). As suggested by the theoretical model, we use the ZEW FCIs reflecting financial market stress as transition variable for both the FCI and IP equation. The maximum tested lag is set to 3, a constant is always included. We do not expect that a higher lag length of the transition variable is economically reasonable in defining the "stress regime" ${ }^{42}$

Selecting the lag length and estimation: We select the lag length by the Schwarz Information criterion based on a linear VAR model, generate starting-values by Differential Evolution in a multivariate framework as suggested by Schleer (2013) and estimate the model by Maximum Likelihood (interior-point algorithm). If there is still serial correlation in the lag structure 43 , we add another lag until the serial correlation test of Teräsvirta and Yang (2013b) with wild-bootstrapped p-values cannot reject the null of no serial correlation. The wild-bootstrap is based on Godfrey and Tremayne (2005).

We bound our estimation problem with respect to the $\gamma$ and $c$ by using 0.5 and 30 as bounds for the slope parameter $(\gamma)$. For the bounds of the the location parameter we use the approach of Schleer (2013) defining the location parameter $c$ for the grid as a function of the transition speed: $\mathbf{C}=f(\boldsymbol{\Gamma})$. If $\gamma$ is high, implying a low number of observations around the threshold, we use a truncated sample of the observations of the transition variable for the location parameter C. Moreover, in our application there are three features which should be considered for finding the location parameter determining the different regimes. First, a value of zero means neutral financial market conditions. Second, the transition variable, the ZEW FCIs, are strongly positively skewed (see Figure 3 and Table 22). Third, high stress occurs less often. If we used a symmetric range to get the support of the transition variable, we would exclude most of or even the complete high stress regime. As a consequence, we take the value which is closest to zero as center (separating negative and positive values) and use the lower $20 \%$ and upper $40 \%$ percentile around this value for finding the threshold $(c) 44$ The chosen asymmetry of the intervals is a consequence of the skewness of the indices.

Table 2: Skewness of ZEW Financial Condition Indices

\begin{tabular}{c|ccccccccccc}
\hline \hline & AUT & BEL & FIN & FRA & GER & GRE & IRE & ITA & NDL & PRT & ESP \\
\hline skewness & 1.928 & 1.871 & 1.502 & 2.004 & 2.010 & 1.137 & 1.995 & 1.621 & 2.183 & 1.855 & 0.595 \\
\hline
\end{tabular}

Evaluation stage: As discussed above, we ensure that our estimated VSTAR models do not exhibit serially correlated error terms. This is a crucial misspecification test in a

\footnotetext{
${ }^{42}$ This is confirmed by the results, as the most frequent lag chosen by the selection procedure is one (see section 3.3 ).

${ }^{43}$ We test serial correlation of order one to twelve.

${ }^{44}$ If the upper $40 \%$ quantile exceeds the support of the realizations of the transition variable, we use a range which excludes the $10 \%$ highest and $60 \%$ lowest values.
} 


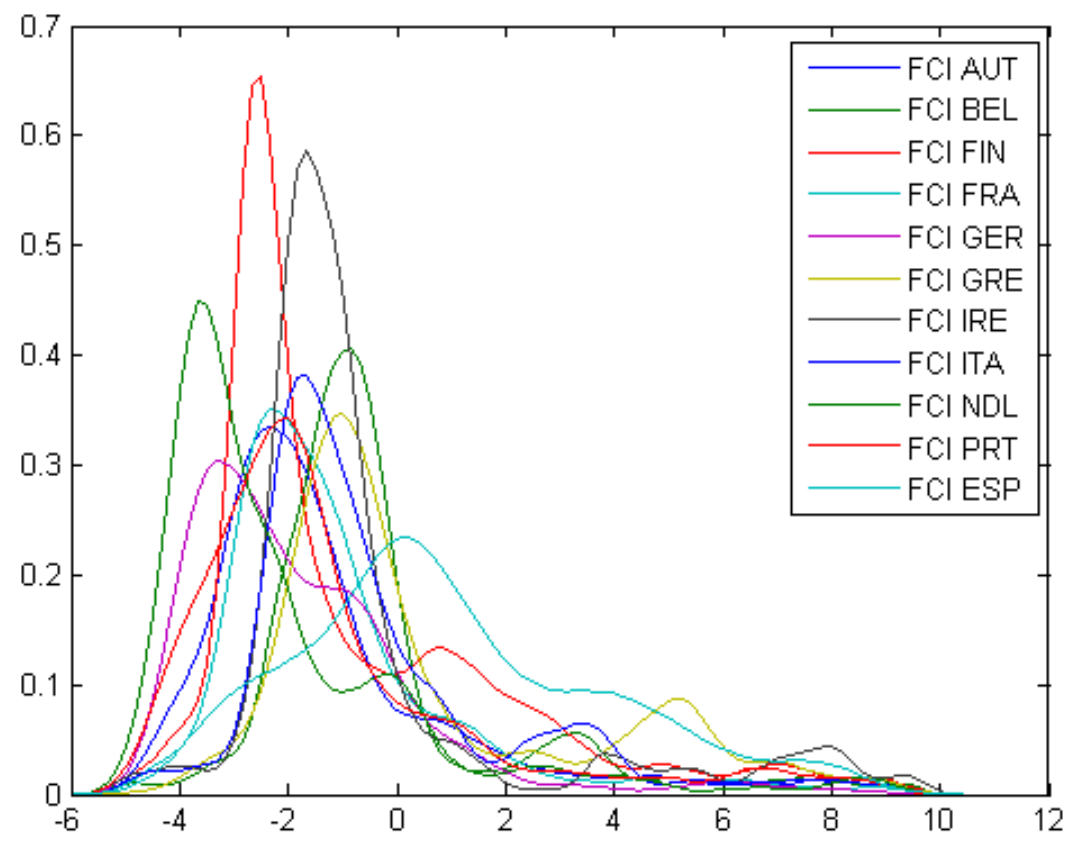

Figure 3: Kernel densities of financial stress indexes, normal kernel, bandwidth optimized for normal kernel, between 0.22 and 0.58

dynamic model in order to rule out inconsistency of parameter estimates caused by serial correlation.

To capture different dynamics across euro area countries and get insights of financial market - macro linkages, we conduct several analyzes. First of all, we model a bivariate Vector STAR model with the ZEW FCIs and industrial production for each country based on financial condition index as transition variable.

We use a bivariate VSTAR model with $y_{t}=[\Delta \log I \mathrm{P}, \mathrm{FCI}]$. Assuming one transition function governing the whole system, we have two different histories (regimes):

$$
\begin{gathered}
\mathrm{FCI}_{t-d}<c(\text { low stress regime) } \\
\mathrm{FCI}_{t-d} \geq c(\text { high stress regime })
\end{gathered}
$$

The non-linear IRFs are not restricted to remain in one regime. In other words, we allow for regime-switching after the initial shock has taken place.

Initially, we perform Granger causality tests which are based on our VSTAR model, thus, taking the non-linearity already into account. Since we rely on a model with two regimes, we technically can "divide" the model in a linear and non-linear part. Hence, we can test Granger causality based on the linear parameters only and on the linear and non-linear parameters. It will be interesting to see whether the dynamics change if we also take the non-linear part represented by their coefficients into account.

Second, we construct non-linear IRFs, namely "Generalized" IRFs, following the method 
of Koop et al. (1996) and Weise (1999) who applied the approach to Vector STAR models. There are important differences between linear and non-linear IRFs: the latter are historydependent, their future shocks may not necessarily be zero, and, they are not invariant to the size and the sign of a shock. We use $B=100$ bootstrap repetition and $R=100$ Monte Carlo replications. By using "Generalized" IRFs, we are able to model asymmetric dynamics with respect to the regime (timing). The non-linear IRFs of the VSTAR model is based on the Cholesky decomposition to derive structural responses. There are two possible factorizations. First, the financial condition index has a contemporaneous effect on industrial production, whereas a shock in industrial production does not affect the financial sector in the same period. For instance, Holló et al. (2012) and van Roye (2011) apply this setting arguing that the current level of IP cannot be observed by market participants due to the publication lag. Hence, the realization cannot be reflected in the variables underlying the FCI.

On the contrary, Mittnik and Semmler (2013) and Hubrich and Tetlow (2012) rely on the reverse ordering. In this case, a variable representing financial market dynamics as the FCI is considered to be fast-reacting to output, whereas output is rather sluggishly adjusting. The latter ordering seems to be more plausible from our point of view, hence, we stick to that form of orthogonalization.

Confidence bands for non-linear IRFs can be constructed by using the empirical distribution function for constructing the $90 \%$ confidence interval for each $h=1, \ldots, H$. A second approach is based on the highest density regions. This concept was developed by Hyndman (1996) and suggested for construction confidence intervals for IRF in non-linear model set-ups by Skalin and Teräsvirta (2002); Teräsvirta et al. (2010). A further possibility is to use box-and-whiskers graphs following Teräsvirta and Yang (2013a). The concepts relies on $R$ GIRFs generated by the Monte Carlo integration procedure and represent these by using box-plots for $50 \%$ (box) and $80 \%$ whisker highest density regions. Yet, none of these methods of constructing confidence bands allows to make inference statements. Due to the IRF construction, the function is a random variable itself. Asymptotic theory has not been explored so far.

\subsection{Results}

Before we discuss the results of Granger causality tests and impulse response functions, we first present the results of the model selection tests, namely, unit root and linearity tests, beginning with the former. Except of the FCI of Portugal, Spain and Ireland, the FCI and IP growth series of all countries are confirmed to be stationary by at least one test 45 Recall that we perform two tests: ERS DF-GLS and ERS point-optimal. Mostly, both tests results coincide indicating stationarity of the time series which is perfectly in line with our expectation that neither IP growth nor FCI exhibit a trend-like behavior.

\footnotetext{
${ }^{45}$ The results can be found in Table 13 in Appendix C
} 
Non-stationarity of the Financial Condition Index of Portugal, Spain and Ireland was found at the $5 \%$ level. We exclude Ireland from our analysis, whereas we adjust the sample for Portugal and Spain as non-stationarity in the FCI series appears to be a more recent phenomena. The FCI indexes of those two countries are steadily increasing after the financial market breakdown due to the sovereign debt crisis setting in quite heavily as well, resulting in non-stationary behavior ${ }^{46}$ The sample periods for each estimated model can be seen in Table3. For these sample periods, the previously mentioned stability condition of a (linear) VAR model is satisfied as well.

Table 3: Sample Periods

\begin{tabular}{l|ll}
\hline \hline Austria & 1980:01 $2013 \mathrm{~m} 01$ \\
Belgium & 1980:01 $2012 \mathrm{~m} 12$ \\
Finland & 1980:01 $2013 \mathrm{~m} 01$ \\
France & 1980:01 $2013 \mathrm{~m} 01$ \\
Germany & 1980:01 $2013 \mathrm{~m} 01$ \\
Greece & 1980:01 $2013 \mathrm{~m} 01$ \\
Italy & 1980:01 $2012 \mathrm{~m} 12$ \\
Netherlands & 1980:01 $2013 \mathrm{~m} 01$ \\
Portugal & 1980:01 $2011 \mathrm{~m} 07$ \\
Spain & 1980:01 $2011 \mathrm{~m} 09$ \\
\hline
\end{tabular}

The null of the joint linearity test (Rao's test statistic) is rejected for each model confirmi ng non-linearities in the financial sector-output dynamics. For the majority of models the lag length of the transition variable was chosen to be one. This has been indicated by the smallest $\mathrm{p}$-value for lag one out of one to three. This is in line with our expectation that a more recent, in terms of its lag, FCI is appropriate for determining the regime in the financial market-output nexus. The only exception is Spain, for which the smallest pvalue was found for lag length three of the transition variable. Overall, joint non-linearity has been detected in the dynamic, interdependent multivariate VSTAR models for all countries 47

In the following section 3.3.1, we present the results of Granger causality tests and impulse response functions for the full sample contrasting linear and non-linear outcomes.

\subsubsection{Linear vs. Non-linear Analysis}

Although the linearity tests confirm our conjecture of a non-linear relation, we derive further insights into differences between linear and non-linear model specification. First, we evaluate whether the different model types yield qualitatively different results. Second,

\footnotetext{
${ }^{46}$ We assume here that the underlying DGPs change essentially. Alternatively, the complete period before could constitute a low stress regime, which empirically does not show non-stationarity. Due to the recent economic development in Spain, Ireland and Portugal with significant distortions in various sectors and unsustainable paths of sovereign debt, for instance, we prefer the former explanation.

${ }^{47}$ In section 3.3 .2 we will discuss the results of the linearity tests in more detail, particulary, their evolution over time.
} 
we analyze the magnitude of differences across linear and non-linear model set-ups. In the following, we discuss the results of Granger causality tests for a linear VAR model and a non-linear VSTAR model. Table 4 presents the results for a linear model. The FCIs Granger cause industrial production in all euro area countries except of Greece and Portugal at a $5 \%$ level of significance. On the contrary, the output variable does not Granger cause the financial market conditions in all countries except for Spain. These results give us a rather clear-cut picture indicating that the FCI is useful in forecasting industrial production, whereas the reverse is not true. Based on a linear VAR model, industrial production does not comprise statistically relevant information for the future situation of financial markets. Moreover, we cannot detect strong cross-country heterogeneity. The overall picture is rather identical for the euro area countries.

Table 4: P-values of Granger causality tests - linear VAR model

\begin{tabular}{l|cc}
\hline \hline country & FCI $\rightarrow$ IP & IP $\rightarrow$ FCI \\
\hline Austria & $\mathbf{0 . 0 1 4 5}$ & 0.5674 \\
Belgium & $\mathbf{0 . 0 0 4 5}$ & 0.8418 \\
Finland & $\mathbf{0 . 0 0 0 0}$ & 0.1984 \\
France & $\mathbf{0 . 0 0 5 1}$ & 0.9289 \\
Germany & $\mathbf{0 . 0 0 0 0}$ & 0.4707 \\
Greece & 0.2022 & 0.7701 \\
Italy & $\mathbf{0 . 0 4 0 8}$ & 0.4434 \\
Netherlands & $\mathbf{0 . 0 0 0 1}$ & 0.3591 \\
Portugal & 0.1008 & 0.8529 \\
Spain & $\mathbf{0 . 0 0 6 2}$ & $\mathbf{0 . 0 4 0 1}$ \\
\hline
\end{tabular}

As linearity tests indicate non-linear behavior, we contrast the VAR-results with Granger causality VSTAR-results. The results for the non-linear Vector STAR models are quite different as can be seen in Table 5. As discussed above, in the Vector STAR model we can test linear and non-linear Granger causality. In the linear case, we test Granger causality based on the linear parameters and in the second case, we test non-linear Granger causality based on linear and non-linear parameters.

First, the results of the linear Granger causality based on the VSTAR model differ clearly from those generated by the linear VAR model. Second, Granger causality between FCI and IP is quiet different by taking also the non-linear parameters into account. This emphasizes the relevance of non-linearities in the financial market-output nexus once more and points out that the differences between linear and non-linear outcomes are qualitatively relevant.

Focussing on the results of the linear and non-linear parameters which describe the whole non-linear model dynamics in Table 5, we detect a significant interdependent financial market-output relations for Austria, Belgium, Spain, Germany, and the Netherlands. This gives support for the adverse feedback look, as it was called by the chairman of the FED Bernanke: not only a shock in financial market conditions results in a significant 
Table 5: P-values of Granger causality tests - non-linear VSTAR model

\begin{tabular}{l|cc|cc}
\hline \hline & \multicolumn{2}{|c}{ linear parameters } & \multicolumn{2}{c}{ linear and non-linear parameters } \\
\hline country & FCI $\rightarrow$ IP & IP $\rightarrow$ FCI & FCI $\rightarrow$ IP & IP $\rightarrow$ FCI \\
\hline Austria & 0.0607 & $\mathbf{0 . 0 0 2 6}$ & $\mathbf{0 . 0 1 5 1}$ & $\mathbf{0 . 0 0 0 0}$ \\
Belgium & 0.2777 & 0.1516 & $\mathbf{0 . 0 0 0 0}$ & $\mathbf{0 . 0 1 6 7}$ \\
Finland & 0.0557 & 0.2845 & $\mathbf{0 . 0 0 0 0}$ & 0.1039 \\
France & 0.2895 & 0.9939 & $\mathbf{0 . 0 0 6 4}$ & 0.4726 \\
Germany & 0.1286 & $\mathbf{0 . 0 3 5 5}$ & $\mathbf{0 . 0 0 0 1}$ & $\mathbf{0 . 0 1 7 1}$ \\
Greece & 0.8831 & 0.1124 & 0.2396 & 0.0971 \\
Italy & 0.4042 & 0.7364 & 0.1495 & 0.2224 \\
Netherlands & $\mathbf{0 . 0 0 5 6}$ & 0.9980 & $\mathbf{0 . 0 0 0 0}$ & $\mathbf{0 . 0 3 0 5}$ \\
Portugal & 0.4954 & 0.0340 & 0.0756 & $\mathbf{0 . 0 1 6 1}$ \\
Spain & $\mathbf{0 . 0 0 0 6}$ & 0.3766 & $\mathbf{0 . 0 0 0 2}$ & $\mathbf{0 . 0 1 0 0}$ \\
\hline
\end{tabular}

long-lasting effect on output, but also the negative economic conditions may feedback on the financial market again. This effect may be neglected if one relies on a linear VAR model which is not able to model a regime change. It can therefore not switch to a regime with negative financial market conditions yielding negative effects for economic activity again as they are also motivated by our theoretical model. Moreover, the results based on the non-linear VSTAR model point towards more heterogeneity across the euro area countries than linear Granger causality does.

Having found further empirical evidence for the relevance of non-linearities which is qualitatively relevant, we compute Impulse Response Functions based on a one standard deviation shock in FCI and report the accumulated response of economic activity after $6,12,18,24$ and 36 months. This is done for both a linear VAR model and non-linear VSTAR model. All linear IRF show the expected results of a, in most cases significant, negative response of industrial production after a shock which worsens the conditions on the financial markets. After 36 months industrial production is for all countries on average $0.78 \%$ lower supporting a long-lasting permanent negative effect on the real economy.

Table 6: Accumulated responses of IP based on linear VAR model after shock in FCI

\begin{tabular}{l|cccccccccc}
\hline \hline & AUT & BEL & FIN & FRA & GER & GRE & ITA & NLD & PRT & ESP \\
\hline $6 \mathrm{~m}$ & $-0.29 \%$ & $-0.47 \%$ & $-0.44 \%$ & $-0.34 \%$ & $-0.67 \%$ & $-0.30 \%$ & $-0.39 \%$ & $-0.44 \%$ & $-0.39 \%$ & $-0.38 \%$ \\
$12 \mathrm{~m}$ & $-0.51 \%$ & $-0.54 \%$ & $-0.88 \%$ & $-0.52 \%$ & $-1.10 \%$ & $-0.51 \%$ & $-0.57 \%$ & $-0.63 \%$ & $-0.57 \%$ & $-0.50 \%$ \\
$18 \mathrm{~m}$ & $-0.66 \%$ & $-0.58 \%$ & $-1.13 \%$ & $-0.61 \%$ & $-1.24 \%$ & $-0.61 \%$ & $-0.57 \%$ & $-0.67 \%$ & $-0.65 \%$ & $-0.43 \%$ \\
$24 \mathrm{~m}$ & $-0.76 \%$ & $-0.61 \%$ & $-1.29 \%$ & $-0.66 \%$ & $-1.28 \%$ & $-0.68 \%$ & $-0.56 \%$ & $-0.64 \%$ & $-0.70 \%$ & $-0.32 \%$ \\
$36 \mathrm{~m}$ & $-0.88 \%$ & $-0.65 \%$ & $-1.44 \%$ & $-0.72 \%$ & $-1.30 \%$ & $-0.77 \%$ & $-0.54 \%$ & $-0.57 \%$ & $-0.79 \%$ & $-0.10 \%$ \\
\hline
\end{tabular}

Italic numbers denote statistically insignificant coefficients, Monte Carlo confidence bands, +/- 2 standard errors.

Yet, in a linear VAR model set-up, we cannot differentiate between different regimes which may influence the outcomes. Linear models can only handle symmetric effects, whereas a non-linear model set-up is able to capture potential asymmetric dynamics within the financial sector-output relation. It is a priori not clear how non-linearities 
influence the relation between the financial sector and the real economy. The negative response in a high (low) stress regime could be higher (lower) due to feed-back effects from the real sector to the financial market which could not be taken into account adequately by a linear model. On the contrary, allowing for regime-switching could lead to smaller negative effects on the macroeconomy. For instance, after 6 or 12 months it may likely be that the economy is faced by at least one regime shift or by another shock hitting the economy. This implies that the initial shock has taken place in a regime of high stress, but it propagates by facing different regimes. Hence, a shift to a low stress regime may dampen the negative consequence on the real economy. In any case, different regimes may change the results and their consideration is important for understanding the financial market-output nexus.

Before we present the results of non-linear IRF, Table 7 shows the values of the optimized threshold and slope parameter for the VSTAR-model. These parameters clearly vary across countries. We also report their standard deviation in order to show their estimation precision.

As can be seen in Figure 4, a smooth rather than an abrupt change takes place for most countries. The optimized slope parameter which determines the transition speed is on a moderate level. Only Italy constitutes an exception showing a rather high transition speed from one to the other regime. The overall finding is in line with our expectation that regime-switching in the financial market-output nexus may be rather smooth. This becomes clear by considering a transition from a high to a low stress regime: A high stress regime will likely not be exited abruptly but the transition may take some time. This result is particularly important for the interpretation of the results of multi-regime VAR or Threshold VAR models which model a sudden regime-change. As indicated by the VSTAR model, the type of non-linearity in the financial market-output relation is different. This may produce misleading results of abruptly swtiching models. The nonlinearities are not as strong and quick as a multi-regime VAR is able to generate. The location parameter is also very heterogenous across countries. In most countries it is above zero. The higher the threshold, the higher the FCI needs to be to switch to a high stress regime. Yet, one has to be cautious with a comparison across countries. The FCIs are country-specific which has also been shown by their different skewness parameters. Hence, the support for the optimization problem differs and the location parameters cannot be easily compared across countries.

Table 7: Optimized location and slope parameter of VSTAR models

\begin{tabular}{l|cccccccccc}
\hline \hline & AUT & BEL & FIN & FRA & GER & GRE & ITA & NLD & PRT & ESP \\
\hline \hline$c$ & 2.03 & 2.58 & -0.55 & 1.56 & 1.29 & -0.59 & -0.29 & 1.48 & 1.36 & 1.63 \\
std.dev. & 1.3115 & 2.2819 & 0.0350 & 0.0610 & 0.4194 & 0.0882 & 0.0014 & 0.0267 & 0.5392 & 0.0365 \\
\hline$\gamma$ & 0.50 & 0.50 & 2.20 & 4.11 & 0.50 & 1.43 & 30.00 & 2.09 & 0.5000 & 3.95 \\
std.dev. & 0.3915 & 0.5073 & 0.0735 & 0.2200 & 0.2338 & 0.1156 & 0.0454 & 0.0490 & 0.2638 & 0.1309 \\
\hline
\end{tabular}




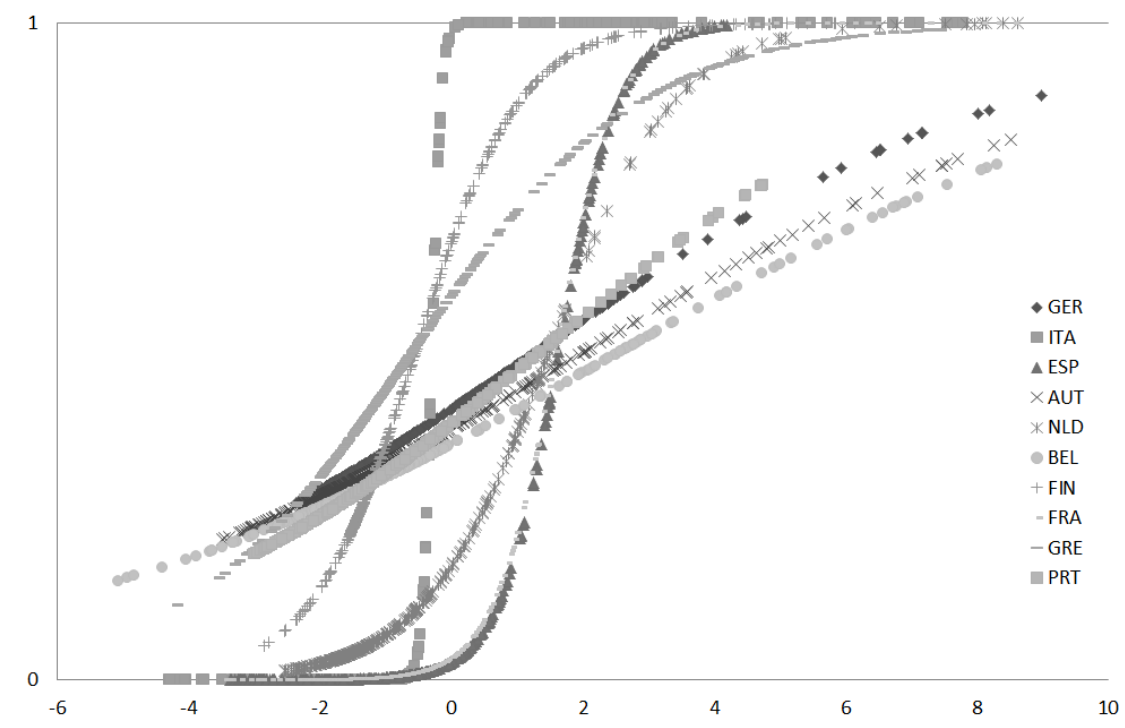

Figure 4: Transition functions for selected euro area countries, VSTAR model

In the following, we present the accumulated responses of IP after a one standard deviation shock in FCI took place for a non-linear VSTAR model (Table 8). The IRFs allow for regime switching which is a reasonable scenario and neglected in some studies. The interpretation is as follows: a shock took place either in a low or high stress regime and the (average) response is calculated without setting future shocks to zero. It is only the shock which has taken place in either regime and it is not the response for a high (low) stress regime. For Germany, Austria, Belgium, Finland, the Netherlands and Portugal, we find a negative response of IP after a shock in the high financial stress regime which is stronger than in the low stress regime confirming non-linear dynamics in the financial sector-output nexus. This is line with the hitherto empirical literature applying Markov Switching models or Multi-regime VARs (see for instance van Roye (2011); Hubrich and Tetlow (2012); Mittnik and Semmler (2013)). Except for Portugal, the responses both for a low and high stress regime shock are smaller than for the linear VAR.

This may likely be a result of allowing for regime switching, not setting future shocks to zero and modeling more flexible transmission mechanisms in the economy. As a consequence, the regime-switching dampens the effect on the real economy, although we allow for non-linear feedback effects of industrial production. For France and Greece, we cannot find a negative reaction of IP after a shock in the financial market. Portugal and Spain show the strongest negative effect in IP after the shock. This is in line with the recent economic development of Portugal and Spain suffering dramatically from the financial market turmoils. Surprisingly, the results of the latter country are stronger if the shock took place in the low stress regime. In Italy the response of IP is negative for both regimes, but it does not influence the results much in which regime the shock has taken place. This may be explained by Italy being a country which has faced many shocks and did not remain in a regime for a long time. 
Bijlsma and Zwart (2013) have classified countries as market-based or bank-based by using a wide-range of indicators. According to them, Germany, Austria, Spain, Italy, Greece and Portugal belong to the latter group. France, Belgium, Finland and the Netherlands are market-based economies. By taking the mean of each group 36 months after a shock, the bank-based economies show a lower mean of $-0.44 \%$ than the market-based countries $-0.27 \%$ after a shock in a low stress regime as well as in a high stress regime $-0.85 \%$ vs. $-0.26 \%$. This gives some empirical evidence that in banking-based economy the recovery after a financial-market shock takes longer and has a more persistent impact on the real economy (see Boissay et al. (2013)).

Table 8: Average of accumulated responses of IP based on bivariate non-linear VSTAR model after shock in FCI

\begin{tabular}{l|cccccccccc}
\hline \hline & AUT & BEL & FIN & FRA & GER & GRE & ITA & NLD & PRT & ESP \\
\hline & \multicolumn{7}{|c}{ low stress } \\
\hline 6 months & $0.15 \%$ & $0.28 \%$ & $-0.35 \%$ & $0.04 \%$ & $-0.31 \%$ & $0.18 \%$ & $-0.25 \%$ & $-0.40 \%$ & $-0.57 \%$ & $-0.61 \%$ \\
12 months & $0.02 \%$ & $0.41 \%$ & $-0.28 \%$ & $0.01 \%$ & $-0.37 \%$ & $0.21 \%$ & $-0.25 \%$ & $-0.50 \%$ & $-0.50 \%$ & $-0.96 \%$ \\
18 months & $-0.06 \%$ & $0.46 \%$ & $-0.30 \%$ & $0.00 \%$ & $-0.38 \%$ & $0.16 \%$ & $-0.17 \%$ & $-0.32 \%$ & $-0.06 \%$ & $-1.13 \%$ \\
24 months & $-0.10 \%$ & $0.39 \%$ & $-0.30 \%$ & $0.00 \%$ & $-0.38 \%$ & $0.19 \%$ & $-0.10 \%$ & $-0.30 \%$ & $-0.95 \%$ & $-1.25 \%$ \\
36 months & $-0.13 \%$ & $-0.43 \%$ & $-0.30 \%$ & $0.00 \%$ & $-0.38 \%$ & $0.17 \%$ & $-0.07 \%$ & $-0.36 \%$ & $-0.75 \%$ & $-1.48 \%$ \\
\hline & & & \multicolumn{7}{c}{ high stress } \\
\hline 6 months & $-0.16 \%$ & $-0.10 \%$ & $-0.81 \%$ & $-0.12 \%$ & $-0.53 \%$ & $0.37 \%$ & $-0.22 \%$ & $-0.58 \%$ & $-0.94 \%$ & $-0.26 \%$ \\
12 months & $-0.20 \%$ & $-0.16 \%$ & $-0.57 \%$ & $0.11 \%$ & $-0.59 \%$ & $0.33 \%$ & $-0.29 \%$ & $-0.40 \%$ & $-0.82 \%$ & $-0.69 \%$ \\
18 months & $-0.23 \%$ & $-0.19 \%$ & $-0.62 \%$ & $0.11 \%$ & $-0.60 \%$ & $0.06 \%$ & $-0.18 \%$ & $-0.19 \%$ & $0.76 \%$ & $-0.92 \%$ \\
24 months & $-0.26 \%$ & $-0.20 \%$ & $-0.61 \%$ & $0.08 \%$ & $-0.59 \%$ & $0.43 \%$ & $-0.08 \%$ & $-0.25 \%$ & $-3.08 \%$ & $-1.04 \%$ \\
36 months & $-0.28 \%$ & $-0.23 \%$ & $-0.61 \%$ & $0.10 \%$ & $-0.59 \%$ & $-0.11 \%$ & $0.01 \%$ & $-0.28 \%$ & $-3.09 \%$ & $-1.04 \%$ \\
\hline
\end{tabular}

Overall, we identify regime-specific dynamics which are not as different and negative as a one may expect and as it was found by previous studies (see, for instance Aboura and van Roye (2013), Hubrich et al. (2013), and Holló et al. (2012)). This results may not only come from the fact that a rather smooth change takes place, but the allowance for regime switching and further shocks may likely dampen the negative effect over time and give us a more realistic picture of the dynamics within economies. Yet, also the underlying time sample may play a crucial role for the results. This issue will be discussed in the following section.

\subsubsection{Non-linearities over time}

To identify potentially changing transmission and amplification mechanisms in the relation between the financial sector and economic activity over time, first, we analyze whether non-linearities constitute a permanent feature in that relation by means of linearity tests. Second, we assess whether there are quantitative differences over time. To assess the latter, we compute rolling impulse response functions (RIRF). RIRFs are an appropriate tool to analyze the evolution of potentially altering dynamics. 
Before the non-linear model is estimated, we check whether the financial condition indices and industrial production constitute indeed a non-linear relation. Rejecting linearity is a necessary condition for estimating a non-linear VSTAR model. If we model a linear relation by a non-linear model, we estimate an unidentified model containing nuisance parameters that are not identified. Hence, it is crucial to ensure by means of a testing procedure that indeed non-linearities can be detected in order to derive valid results.

We start at the beginning of 1995 and estimate the country-specific VSTAR model of FCI and IP with increasing window sample size. Starting in 1995 aims at balancing the trade-off between the number of observations which are necessary to reliably estimate the VSTAR model and the time horizon for which the different VSTAR models can be calculated. The former requires a sample period which is as long as possible.

From an economic perspective, it would be interesting to estimate the RIRFs for a sample which ends earlier to get further insights in potentially changing dynamics. For instance, a sample which ends before the Black Monday of 1987. Starting in 1995:01 leaves us with 180 observations for the first VSTAR model being a good compromise.

Stationarity tests, lag selection and estimation strategy are as described above. Based on the (rolling) unit roots tests, we excluded Ireland in our analysis as the FCI series suffers from non-stationarity over a significant time period. For some other countries, we adjusted the sample if we observe a unit root or unstable behavior of the VSTAR model. ${ }_{4}^{48}$

We compute rolling linearity tests based on Rao's statistic. The results of the rolling linearity tests are discussed in the following and reported in Table 9. Belgium, Finland, France and Portugal show highly non-linear dynamics in the financial sector-output link over the complete rolling sample. Linearity is rejected at a $1 \%$ level of significance. For the second group of countries, comprising of Germany, Greece and the Netherlands the null of linearity is rejected most of the time at a $1 \%$ or $5 \%$ level of significance. There are few exceptions for Germany and the Netherlands for which linearity can only be rejected at the $10 \%$ level. Nevertheless, we take this as empirical evidence that also these three countries exhibit non-linear dynamics in the financial market-macro link. Spain, Austria, and Italy constitute the third group. Before the financial crisis break-out, we cannot reject the null of linearity at a usual level of significance. Yet, after the collapse for Austria, Italy and partly Spain exhibit non-linear dynamics in the financial market-output relation. The pattern which is most clear for the latter three countries, a decrease in the p-value after the Lehman collapse, is qualitatively identical across most euro area countries. The latter result can be found in Table 9. The average of pre-crisis p-values is clearly higher than for the crisis period. Hence, non-linearities become (more) evident ${ }^{49}$ Except of Austria, Italy and Spain, the countries also exhibit non-linear dynamics before the collapse, where the latter group switches from linearity to non-linearity.

\footnotetext{
${ }^{48}$ The exclusions we made are reported in Table 14 in Appendix D

${ }^{49}$ Belgium, Finland, and Greece may be declared as an exception. The p-values are extremely low before such that a significant further drop cannot be observed.
} 
This result may indicate that the non-linearities in the financial-market output relation may not be present or be weaker before the financial crisis break-out due to the drop in the p-value afterwards 50 For most series the underlying (full sample) process appears to be non-linear. By focussing on subsamples, this is not necessarily the case. In particular, conditional on being only in a low stress regime the interplay between FCI and IP should be only linear. This may likely be the rational behind the switch to a non-linear relation after the Lehman collapse. We can take away from the linearity tests that the financial sector-output nexus does not always exhibit inherent non-linearities. There is heterogeneity across countries. This has to be checked thoroughly. Moreover, declining p-values from the pre-crisis to the crisis sample indicate a change in the dynamic behavior and amplification mechanisms.

Table 9: Mean of p-values of rolling linearity tests (Rao's statistic)

\begin{tabular}{l|cccccccccc}
\hline \hline & AUT & BEL & FIN & FRA & GER & GRE & ITA & NLD & PRT & ESP \\
\hline full sample & 0.26772 & 0.0000 & 0.0000 & 0.00001 & 0.00628 & 0.0000 & 0.10902 & 0.00590 & 0.00002 & 0.30138 \\
pre-crisis sample & 0.35425 & 0.0000 & 0.0000 & 0.00001 & 0.00812 & 0.0000 & 0.14141 & 0.00774 & 0.00002 & 0.33038 \\
crisis sample & 0.0000 & 0.0000 & 0.0000 & 0.0000 & 0.0000 & 0.0000 & 0.00389 & 0.0000 & 0.00004 & 0.17286 \\
\hline
\end{tabular}

Full sample refers to 1980m1:2013m1 (exceptions see Table 14), the pre-crisis sample to 1980m1:2008m8 and the crisis sample to 2008m09:2012m12.

To investigate the evolution of non-linearities further, we compute rolling non-linear IRFs for those countries exhibiting non-linearities over the whole sample period. Those countries are Belgium, Finland, France, Portugal, Germany, Greece, and the Netherlands. We leave out Spain, Italy, and Austria. The linearity tests have already shown that we cannot detect regime-specific dynamics before the financial market meltdown. Hence, we observe a qualitative differences with linear behavior before and non-linear behavior after the Lehman collapse. For Belgium, Finland, France, Portugal, Germany, Greece, Netherlands we analyze whether, although we observe non-linear behavior over the whole sample period, quantitative differences arise in the financial market-output nexus.

Results are presented in more detail for Germany in the following. We discuss the results of France, Greece, the Netherlands, Finland, and Belgium as well. The detailed results of the latter countries can be found in Appendix D $]^{51}$

In Figures 5 and 6, the rolling impulse response functions for Germany show a highly interesting pattern. Before the Lehman collapse, hence, up to September 2008, a shock in the financial sector which is represented by the ZEW FCI does not lead to a negative

\footnotetext{
${ }^{50}$ It further stands out that if linearity is rejected, the test selects lag length one of the FCI to be the transition variable in $76 \%$. This further confirms our conjecture that a FCI with a shorter delay determines the regime.

${ }^{51}$ The financial sector-output nexus of Portugal shows instabilities which may come from insufficient sample length to reliable estimate these rolling impulses or explosive behavior due to non-stationarity of the system. Hence, we do not present those results. Recall that we test non-stationarity of the individual series but we cannot test non-stationarity of the whole VSTAR system as the econometric theory is not developed so far. Nevertheless, also these results confirm once more the high sensitivity with respect to the actual sample (size).
} 
response of industrial production in Germany. Neither the shock in the low nor in the high stress regimes - as they are defined here by the model - resulted in a response which is persistent or even negative. The financial crisis looks like a structural break in the financial sector-output relation. The dynamics are clearly changing after the financial sector is under strain as a results of the Lehman breakdown. As from September 2008 on, the response of IP is clearly negative and economic activity persistently remains on a lower level. The dot-com bubble, an event which also puts the financial market in Germany under pressure, for instance, does also not result in remarkable and persistent consequences on the real economy. From that perspective, the financial crisis 2008 appears as an "outlier event".

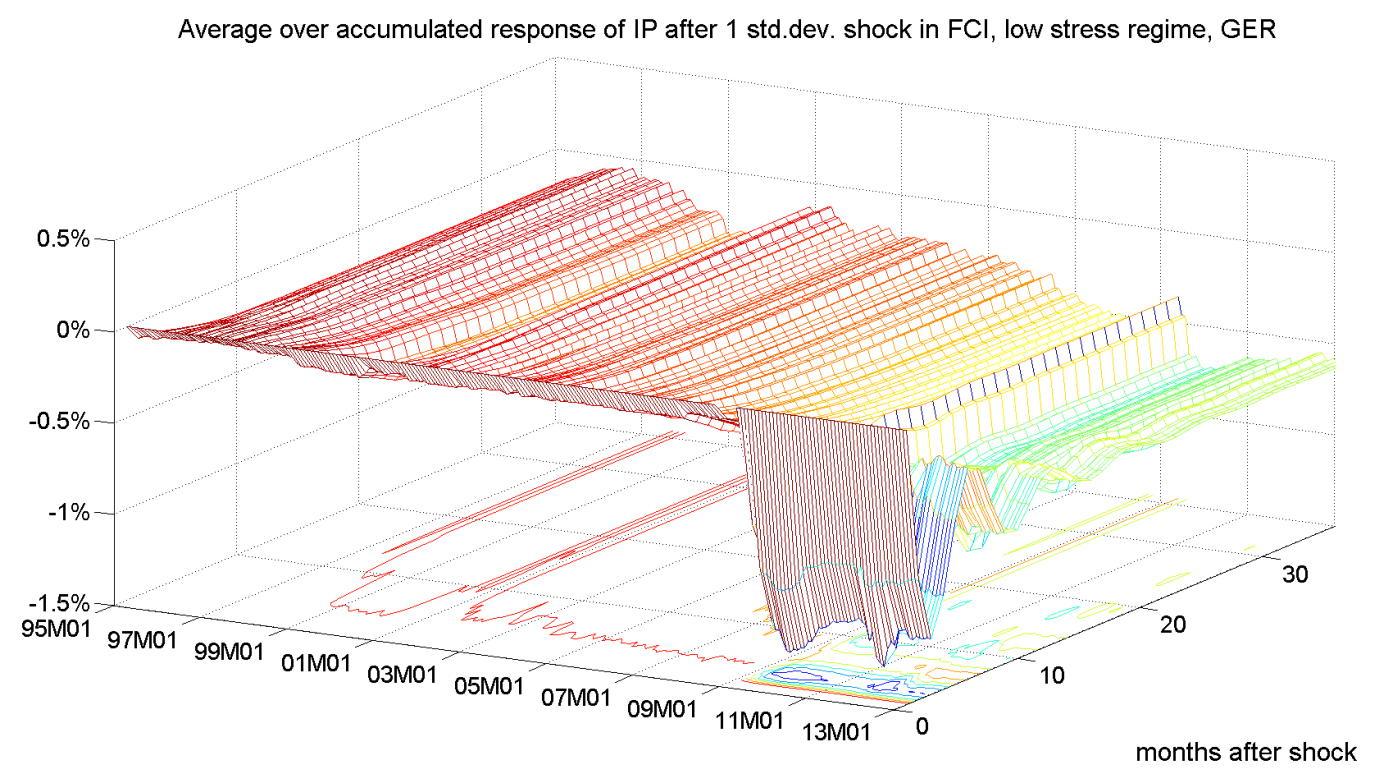

Figure 5: Rolling IRFs of IP, Germany, low stress regime

To get more quantitative insights into the results, we calculated the mean of all rolling IRFs for $6,12,18,24$ and 36 months after the initial shock has taken place. We analyze the results for three different periods: the full sample 1980:01 - 2013:01, the pre-crisis sample 1980:01 - 2008:08 and the crisis sample 2008:09 - 2013:01. We compare the mean of the RIRFs across regimes. Surprisingly, the mean after a shock in the low stress regime is lower for the full and the pre-crisis sample. This indicates that in a low stress regime the consequences for the real economy were more negative which contradicts the results of the hitherto theoretical and empirical literature. After the Lehman breakdown, the crisis period, the IRFs show the expected and in the hitherto literature described results of asymmetric significant, negative responses across high and low stress regimes. An interpretation of this result could be, that first, before the crisis non-linearities in the financial-sector output link may not be as prominent as they are after the Lehman collapse. Second, the estimation of low vs. high stress need to be qualified. Before the Lehman collapse there may have been not such "high" stress situation such that strong 


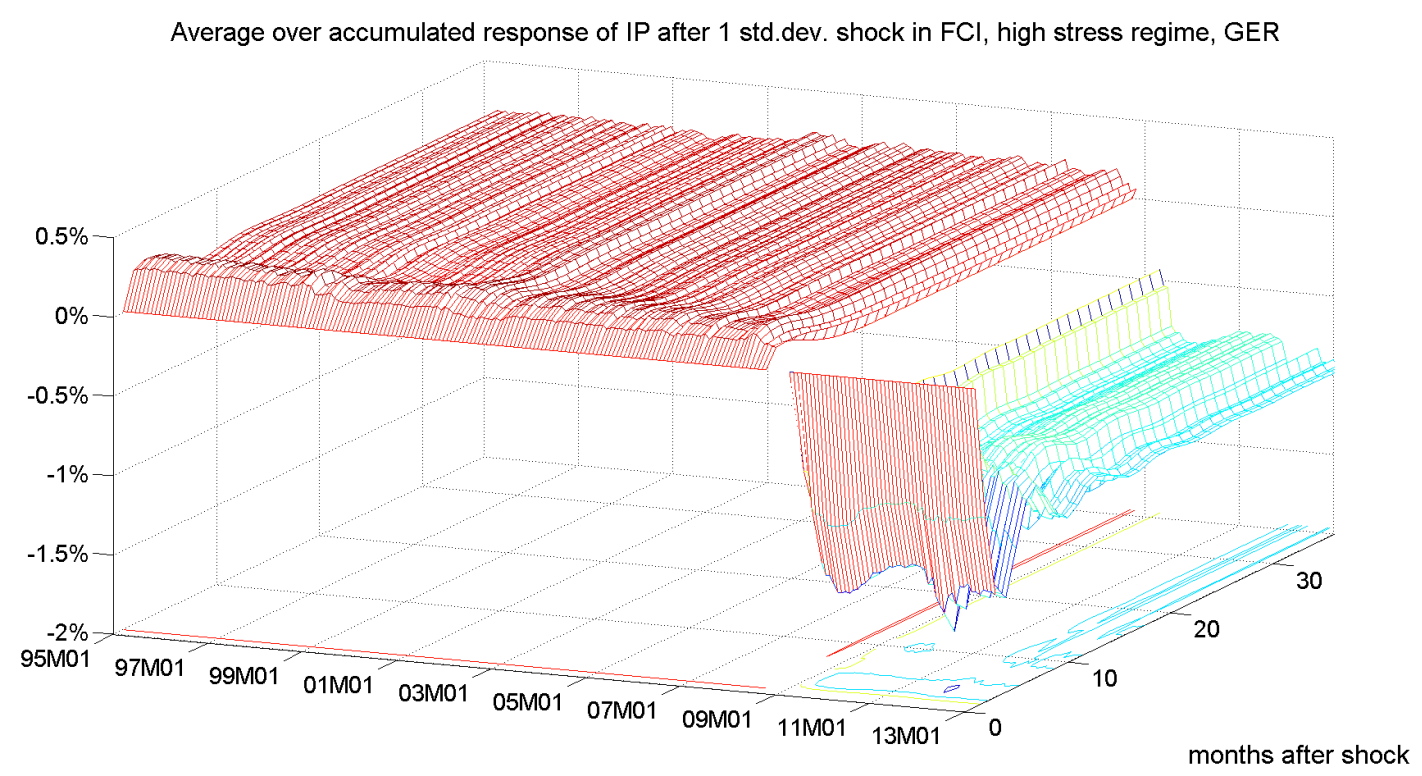

Figure 6: Rolling IRFs of IP, Germany, high stress regime

amplification mechanisms have been triggered.

Table 10: Average over accumulated response of IP after 1 std.dev. shock in FCI, Germany

\begin{tabular}{l|cc|cc|cc}
\hline & \multicolumn{2}{|c}{ full sample } & \multicolumn{2}{c}{ pre-crisis sample } & \multicolumn{2}{c}{ crisis sample } \\
\hline & low stress & high stress & low stress & high stress & low stress & high stress \\
\hline 6 months & $-0.27 \%$ & $-0.06 \%$ & $-0.22 \%$ & $0.13 \%$ & $-0.44 \%$ & $-0.66 \%$ \\
12 months & $-0.36 \%$ & $-0.09 \%$ & $-0.28 \%$ & $0.13 \%$ & $-0.62 \%$ & $-0.84 \%$ \\
18 months & $-0.39 \%$ & $-0.10 \%$ & $-0.30 \%$ & $0.13 \%$ & $-0.67 \%$ & $-0.88 \%$ \\
24 months & $-0.39 \%$ & $-0.10 \%$ & $-0.31 \%$ & $0.13 \%$ & $-0.68 \%$ & $-0.88 \%$ \\
36 months & $-0.40 \%$ & $-0.10 \%$ & $-0.31 \%$ & $0.13 \%$ & $-0.68 \%$ & $-0.88 \%$ \\
\hline
\end{tabular}

Full sample refers to 1980m1:2013m1, the pre-crisis sample to 1980m1:2008m08 and the crisis sample to 2008m09:2013m1.

This effect has not been discussed in the literature. One may ask, whether the financial crisis is only a larger shock or whether the amplification mechanisms are changing after the Lehman collapse or both. Based on our results, the shock propagation and dynamics have clearly changed. Yet, the shock size is always one standard deviation, which is significantly increasing in the course of time (see figure 7). This roughly holds for the other countries as well (see Figure 12). What is most clear is that the shock size increases after the Lehman breakdown.

To analyze whether the change in the dynamics and intensity of the negative response of the real economy is purely driven by the size of the shock, we also calculate RIRF where we control for the shock size, i.e. we normalize the shock size to be 0.2348 for all RIRFs. This is the mean of the (one standard deviation) shock of the rolling window sample from 1995:01 to 2013:01 for Germany.

As can be seen from Figures 8 and 9 , it is obviously not only the size of the shock 


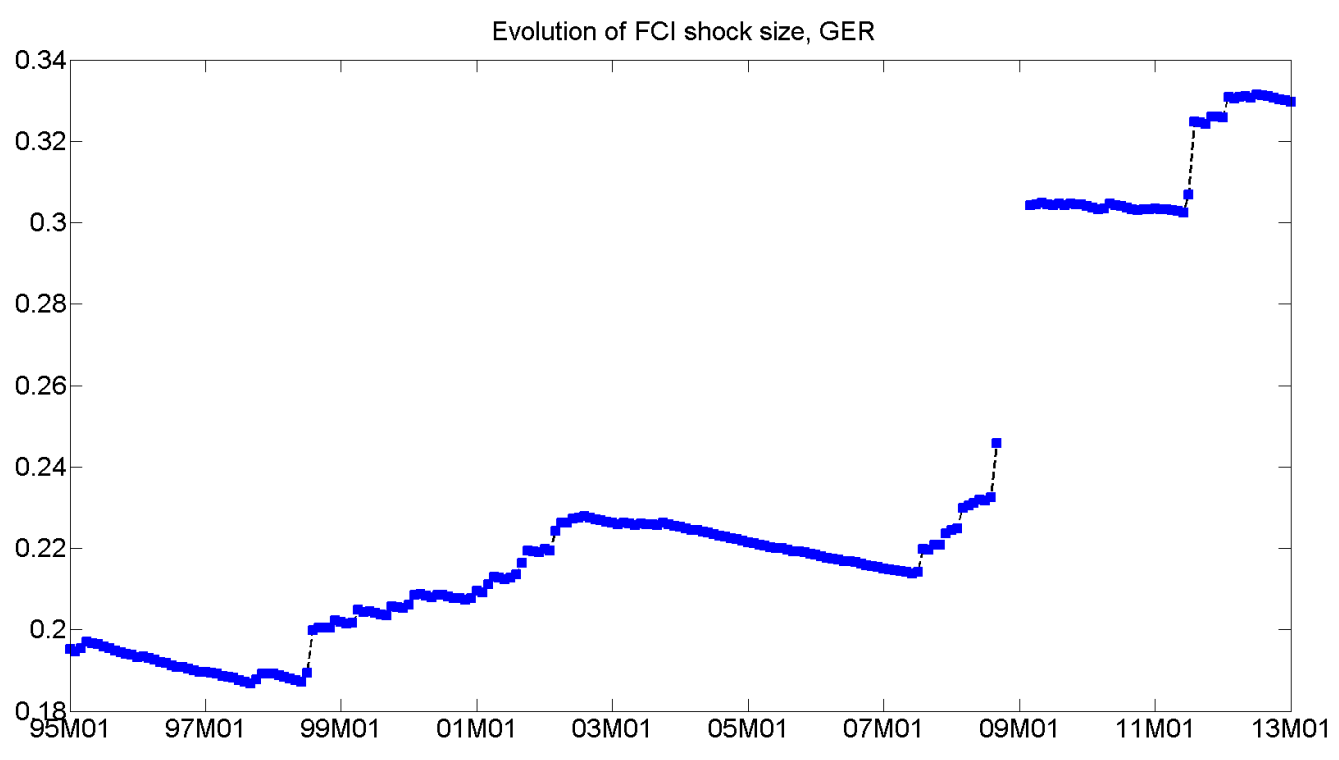

Figure 7: Shock size of FCI, Germany

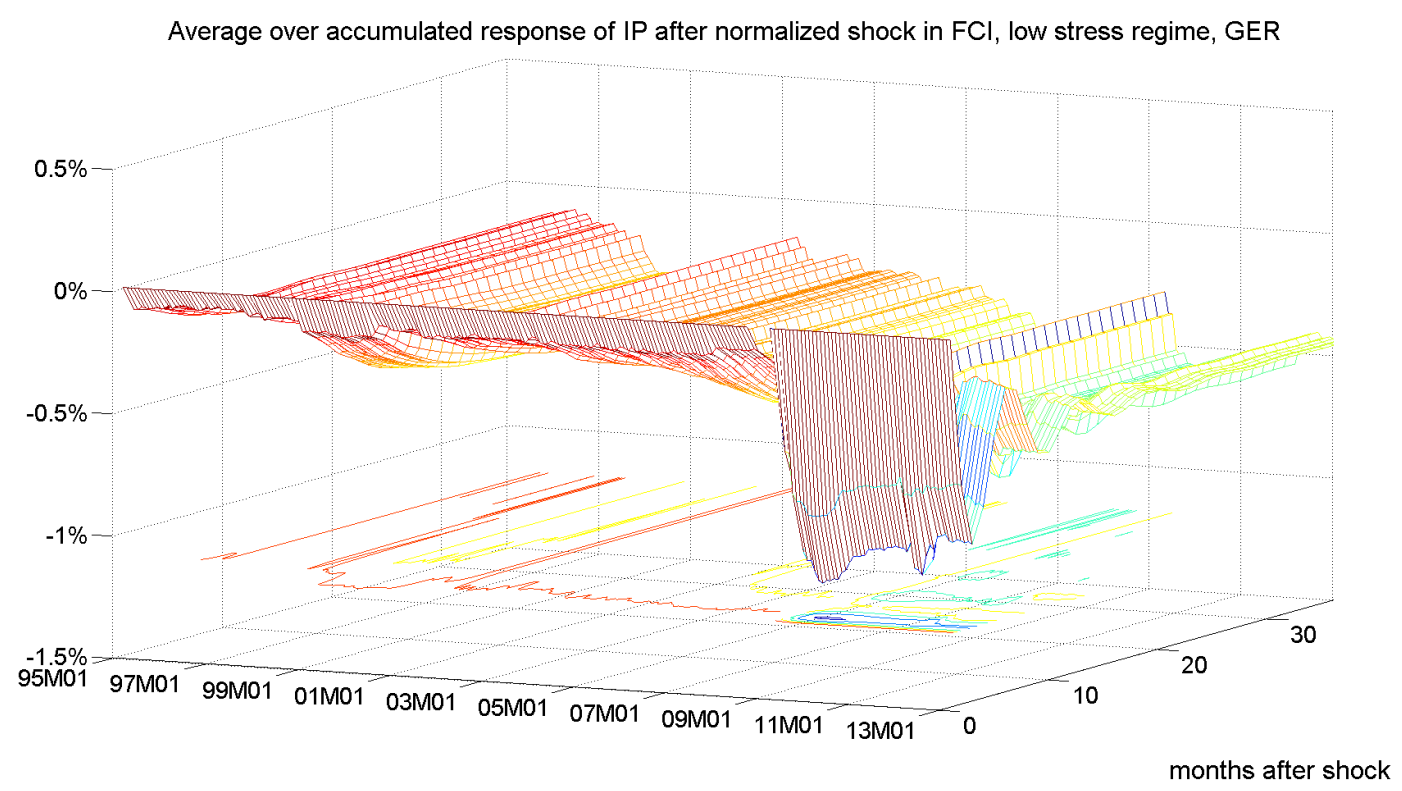

Figure 8: Rolling IRFs of IP, normalized shock, Germany, low stress regime 


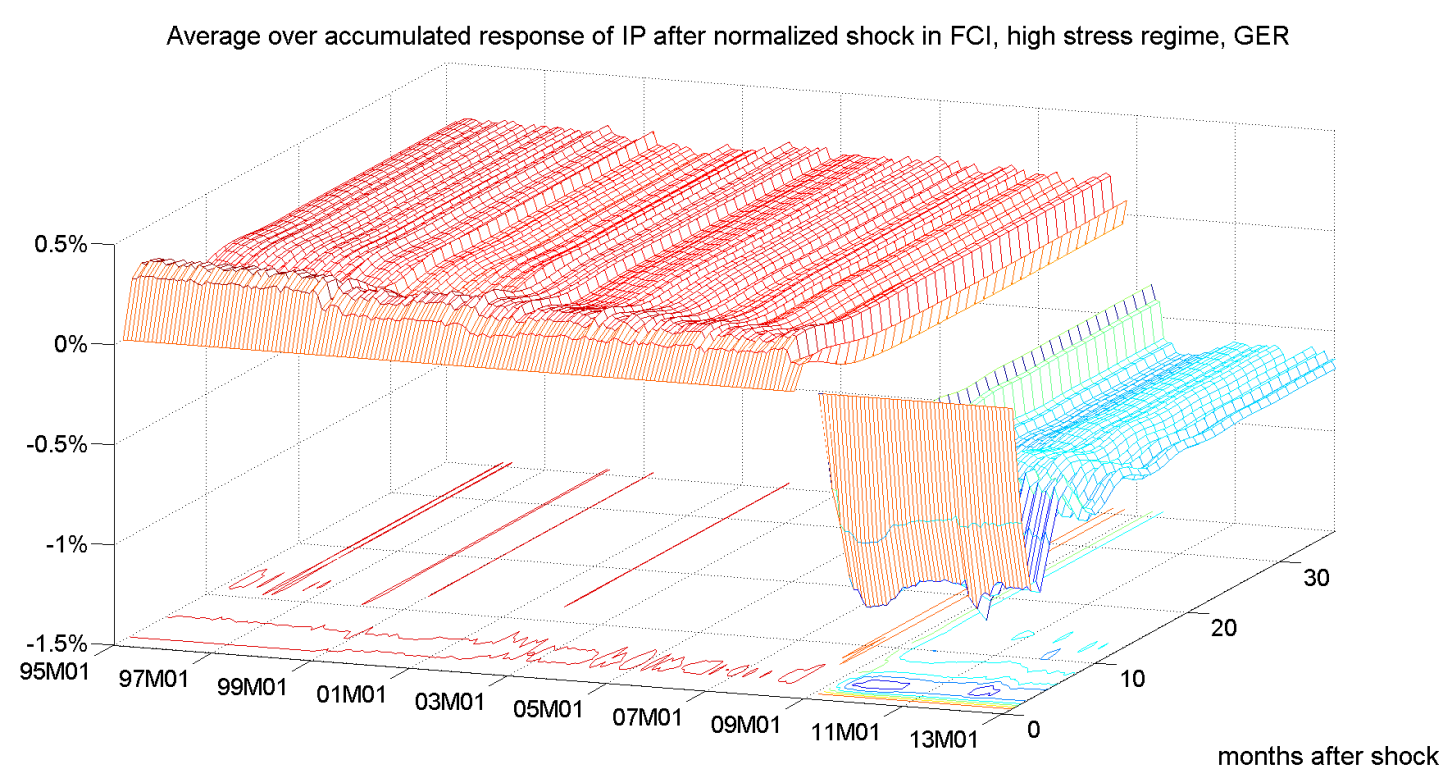

Figure 9: Rolling IRFs of IP, Germany, normalized shock, high stress regime

which matters. There have been also systematic changes in the amplification mechanisms compared to normal times. Although we control for the size of the shock, the dynamics clearly change after the Lehman breakdown independent of the regime in which the shock took place. This is in contrast to results derived by Benati (2013). He argues that financial crises results in very similar macro fluctuations as they are in normal times, but only the size of the shock matters. Yet, Benati (2013) does not account for a stochastic regimeswitching, hence non-linear behavior, which most likely does not model the dynamics after the Lehman shock adequately. The sample-specific means confirm those derived with non-normalized shocks (see Table 11).

Table 11: Mean of accumulated response of IP after normalized shock in FCI, Germany

\begin{tabular}{l|cc|cc|cc}
\hline & \multicolumn{2}{|c}{ full sample } & \multicolumn{2}{c}{ pre-crisis sample } & \multicolumn{2}{c}{ crisis sample } \\
\hline & low stress & high stress & low stress & high stress & low stress & high stress \\
\hline 6 months & $-0.26 \%$ & $0.00 \%$ & $-0.24 \%$ & $0.14 \%$ & $-0.33 \%$ & $-0.49 \%$ \\
12 months & $-0.34 \%$ & $-0.03 \%$ & $-0.31 \%$ & $0.15 \%$ & $-0.47 \%$ & $-0.62 \%$ \\
18 months & $-0.37 \%$ & $-0.04 \%$ & $-0.33 \%$ & $0.15 \%$ & $-0.51 \%$ & $-0.65 \%$ \\
24 months & $-0.38 \%$ & $-0.04 \%$ & $-0.34 \%$ & $0.15 \%$ & $-0.51 \%$ & $-0.66 \%$ \\
36 months & $-0.38 \%$ & $-0.04 \%$ & $-0.35 \%$ & $0.15 \%$ & $-0.51 \%$ & $-0.65 \%$ \\
\hline
\end{tabular}

Full sample refers to 1980m1:2013m1, the pre-crisis sample to 1980m1:2008m8 and the crisis sample to 2008m09:2013m1.

The results obtained hold for France, Finland, and Belgium as well. We present the normalized shock response in Appendix D. After 2008:09 the response of industrial production is clearly negative although we control for the shock size, whereas it varies around zero before. This confirms our conclusions drawn before. For Greece and the Netherlands the results are not as unambiguous as for the latter countries. Yet, we observe also here changing dynamics after Lehman collapse. 
First, the stronger amplification mechanisms may arise after the Lehman collapse, describing asymmetric behavior in the financial sector-output link which might have not been present before. Second, the Lehman breakdown may constitute a structural break in the link between the financial sector and economic activity making it necessary to work with non-linear models. The "outlier event" Lehman brothers and the following Euro crisis could also constitute a new situation in the financial sector-output nexus which prevails. This is also confirmed by following Figure 10 which shows the value of the location parameter over time. The value remains on a low level before it rises strongly after the financial crisis break-out. The optimized location parameter for the other countries can be found in the Appendix $\mathrm{D}$. The pattern, that there is an increasing threshold value, is confirmed for the analyzed countries. In contrast to Germany, the threshold value is even further increasing recently.

The outcomes lead to the question whether we really capture "high" financial stress before or whether the amplification mechanisms were weaker. As to the first point, we can take a look at the location parameter. For Germany, France, the Netherlands, and Belgium it remains on a rather low level before the Lehman collapse, whereas it is already quite high in Finland and Greece in the 90s. As to the second point, the weaker amplification mechanism before the Lehman break down, this is also likely but cannot be explored here further because of a lack of detailed data.

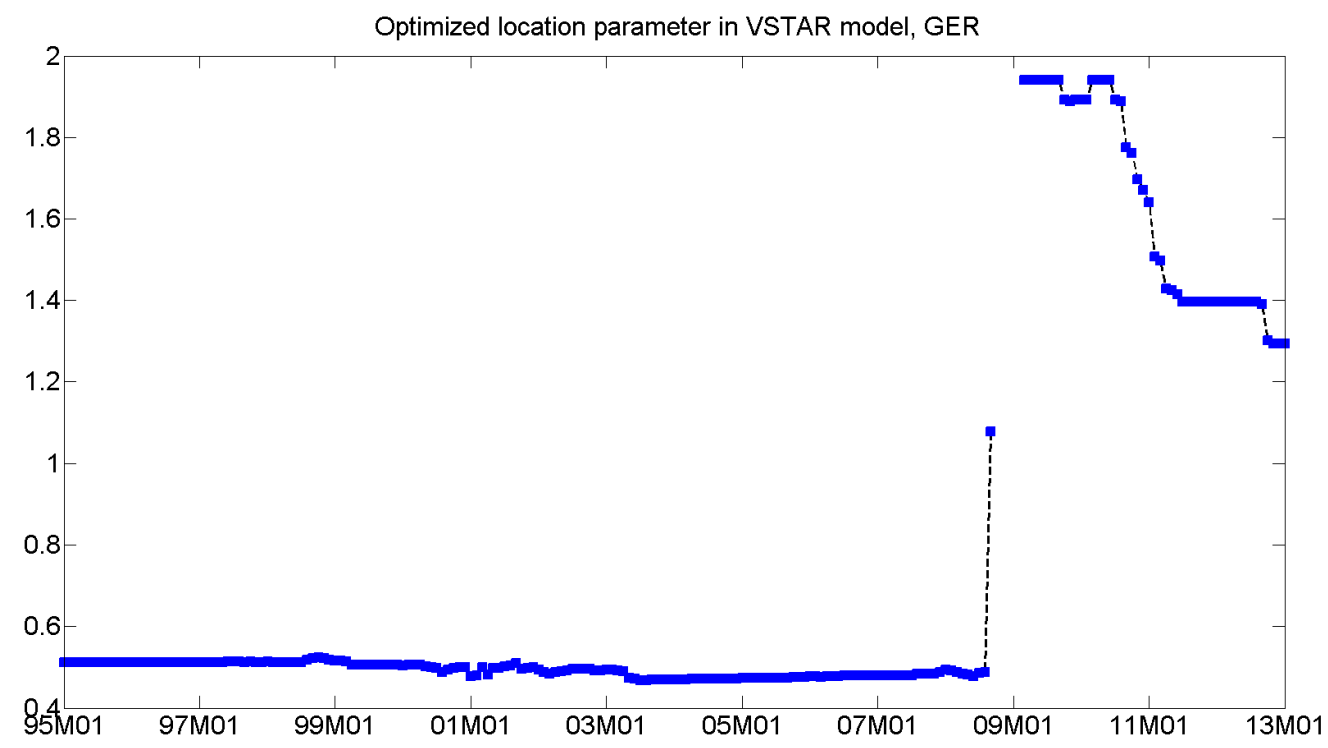

Figure 10: Optimized location parameter VSTAR model, Germany

We suggest that our findings are in line with the financial cycle interpretation in the sense of Jordà et al. (2011) and Schularick and Taylor (2012): events leading to a strong economic breakdown as consequence of a financial market crisis are related rather to a financial cycle which has a low frequency and hence, occur rarely. The hitherto empirical finding - a shock in the financial sector leads to a stronger negative effect on the real 
economy in a high "stress" regime than in a low one - has to be interpreted with more caution. This is in particular important for short samples. The negative output effect may not always be present although we are in a model-defined "high stress" regime. The difficulty is to find out what kind of "high stress regime" leads to such negative consequences. Thus, it is not only the difficulty to differentiate between high and low stress regimes but also to identify relevant (for the real economy) stress regimes.

\section{Conclusion}

We confirm the relevance of non-linearities in the financial sector-output relation by a Vector STAR model based on the data sample from 1980:01 to 2013:01 by using new Financial Condition Indices. It appears to us that an important clue for a loss of stability can be found in the stability of the banking system. That is why we have constructed new indices.

In most countries, a shock in the financial market leads to a long-lasting negative response in economic activity which is regime-dependent. Yet, the negative response is not as pronounced as it is in other studies. This may first result from regime changes taking place rather smooth than abrupt. Shocks in the presence of smooth regime-changing may be dampened so that the negative effect on economic activity is weaker. Second, the outcomes hinge centrally on the sample period. We show that dynamics in the financial market-macroeconomy link vary over time in the euro area countries. Linearity cannot be rejected for some euro area countries over time questioning non-linearities in the financial sector-output nexus as unambiguous feature. Declining p-values point towards increasing importance of non-linearities with the financial crisis break out. Even if linearity is rejected, the negative output effect typically observed is not always present. In particular, it is not continually found before the Lehman collapse, although we are in a model-defined high stress regime. This suggests that events leading to a strong economic breakdown are rather related to a financial cycle which has low frequency and hence, occur rarely. The difficulty is to determine what kind of high stress regimes lead to such stronger amplification. One has to differentiate not only between high and low stress regimes but also to identify relevant stress regimes (for the real economy) and their amplification mechanisms.

Yet, we do not set-up a complete structural model in the empirical sense but describe in a bivariate non-linear VSTAR model the connection between financial market conditions and the real economy. As the link between both is still not fully understood in theory, it is important for model builders to have some empirical insights in order to better understand the dynamics. 


\section{A The Numerical Procedure}

For the numerical solution of our dynamic decision problem we employ a new procedure. Usually one uses DYNARE or Dynamic Programming to solve models such as presented in section 2, see Grüne and Semmler (2004). DYNARE linearizations work with first or second order approximation and eliminates the non-linearities. Though DP may be superior, but its numerical effort typically grows exponentially with the dimension of the state variable. Hence, even for moderate state dimensions it may be impossible to compute a solution with reasonable accuracy. A remedy to this problem can be obtained by using nonlinear model predictive control (NMPC), which is the method we use in this paper, see Grüne et al. (2013). Instead of computing the optimal value function for all possible initial states, NMPC only computes single trajectories.

In order to describe the method, let us abstractly write the dynamic decision problem as

$$
\operatorname{maximize} \int_{0}^{T} e^{-\rho t} \ell(x(t), u(t)) d t,
$$

where $x(t)$ satisfies $\dot{x}(t)=f(x(t), u(t)), x(0)=x_{0}$ and the maximization takes place over a set of admissible decision functions. By discretizing this problem in time, we obtain an approximate discrete time problem of the form

$$
\operatorname{maximize} \sum_{i=0}^{T} \beta^{i} \ell\left(x_{i}, u_{i}\right) d t
$$

where the maximization is now performed over a sequence $u_{i}$ of decision values and the sequence $x_{i}$ satisfies $x_{i+1}=\Phi\left(h, x_{i}, u_{i}\right)$. Here $h>0$ is the discretization time step, $\beta=e^{-\rho h}$ and $\Phi$ is a numerical scheme approximating the solution of $\dot{x}(t)=f(x(t), u(t))$ on the time interval $[i h,(i+1) h]$. For details and references in which the error of this discretization is analyzed we refer to Grüne et al. (2013).

The idea of NMPC now lies in replacing the maximization of the above large horizon functional, where we could have $T \Rightarrow \infty$, by the iterative maximization of finite horizon functionals

$$
\operatorname{maximize} \sum_{k=0}^{N} \beta^{i} \ell\left(x_{k, i}, u_{k, i}\right) d t,
$$

for a truncated finite horizon $N \in \mathbb{N}$ with $x_{k+1, i}=\Phi\left(h, x_{k, i}, u_{k, i}\right)$ and the index $i$ indicates the number of the iteration, cf. the algorithm below. Note that neither $\beta$ nor $\ell$ nor $\Phi$ changes when passing from (15) to (16), only the horizon is truncated.

Problems of type (16) can be efficiently solved numerically by converting them into a static nonlinear program and solving them by efficient NLP solvers, see Grüne and Pannek (2011).

Given an initial value $x_{0}$, an approximate solution of 15 can now be obtained by 
iteratively solving (16) as follows:

(1) for $\mathrm{i}=1,2,3, \ldots$

(2) solve (16) with initial value $x_{0, i}:=x_{i}$ and denote the

resulting optimal control sequence by $u_{k, i}^{*}$

(3) $\quad$ set $u_{i}:=u_{0, i}^{*}$ and $x_{i+1}:=\Phi\left(h, x_{i}, u_{i}\right)$

(4) end of for-loop

This algorithm yields an infinite trajectory $x_{i}, i=1,2,3, \ldots$ whose control sequence $u_{i}$ consists of all the first elements $u_{0, i}^{*}$ of the decision sequences for the finite horizon subproblems (16).

Under appropriate assumptions on the problem, it can be shown that the solution $\left(x_{i}, u_{i}\right)$ (which depends on the choice of $N$ above) converges to the correct solution of 15 as $N \rightarrow$ $\infty$. The main requirement in these assumptions is the existence of an equilibrium for the infinite horizon problem (15). If this equilibrium is known, it can be used as an additional constraint in (16), in order to improve the convergence properties. However, recent results have shown that without a priori knowledge of this equilibrium this convergence can also be ensured, see Grüne et al. (2013), and this is the approach we use in the computations in this paper.

\section{B The Data}

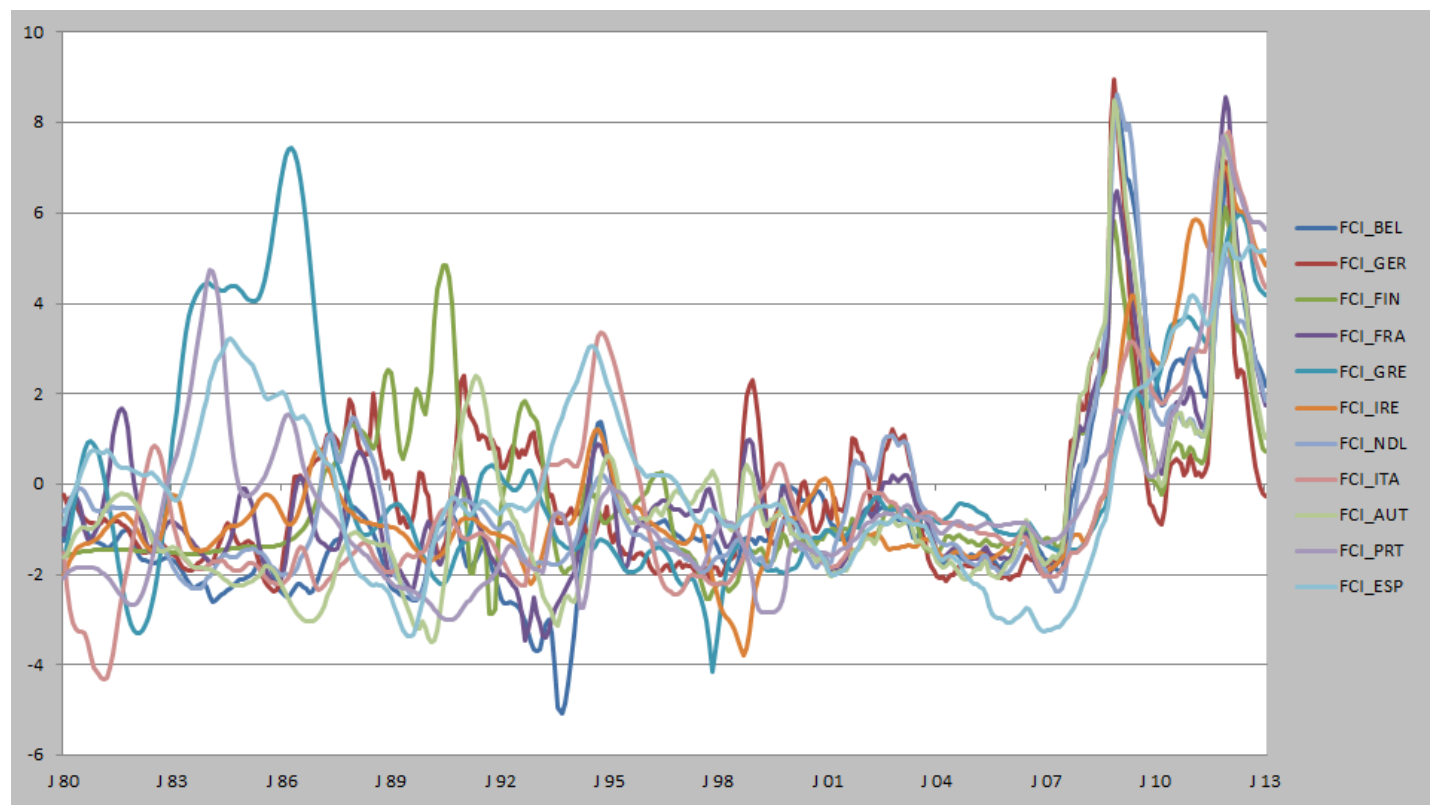

Figure 11: FCIs of selected euro area countries

In Table 12 follows a brief description of variables used to extract the ZEW FCIs divided into three groups, namely, the banking sector (variables related to the money and interbank market, credit conditions and constraints, balance sheet structure of banks, and bank's profitability situation), security market and foreign exchange market. We also 
report the transformation which were used to make the series stationary, the native frequency, the source $(\mathrm{D}=$ Datastream; $\mathrm{ECB}=$ European Central Bank), the first observation if the series is a euro area aggregate and not country-specific and a note if the series is a euro area (EA) aggregate. 


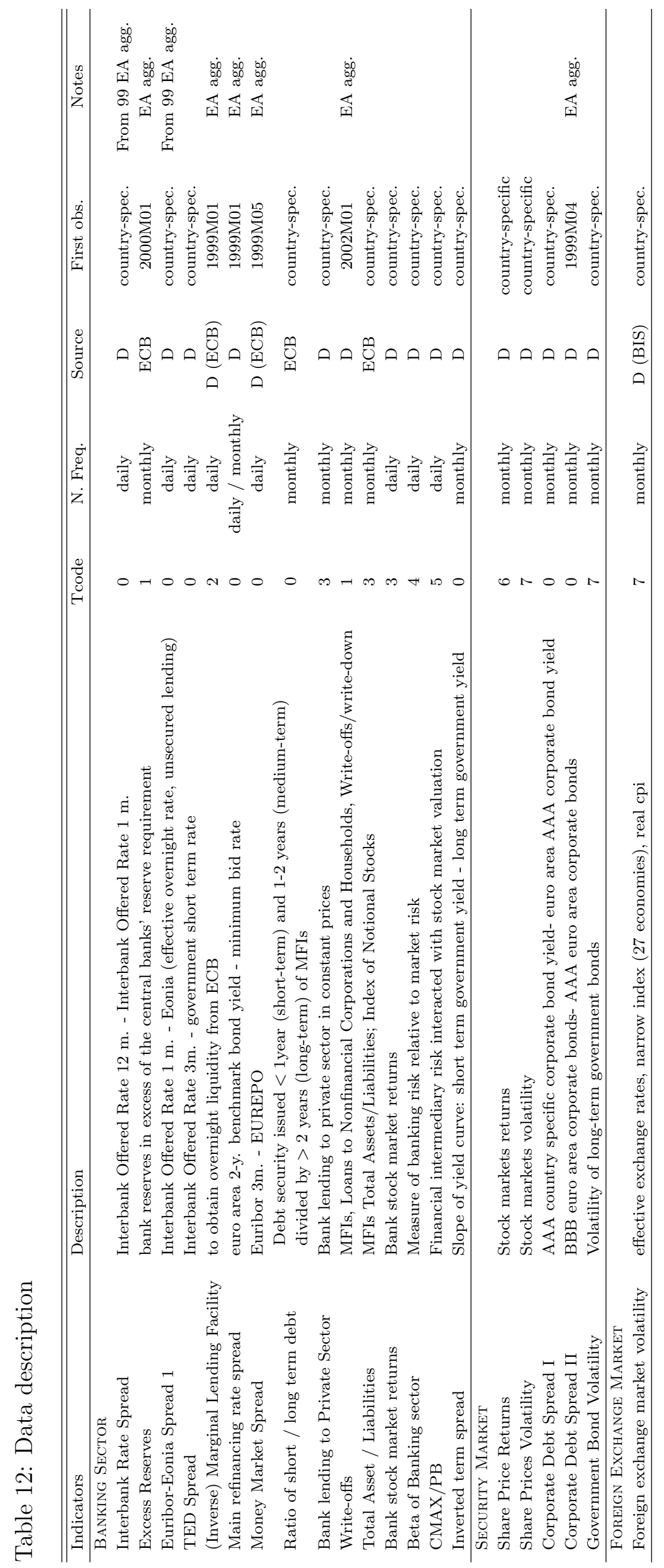

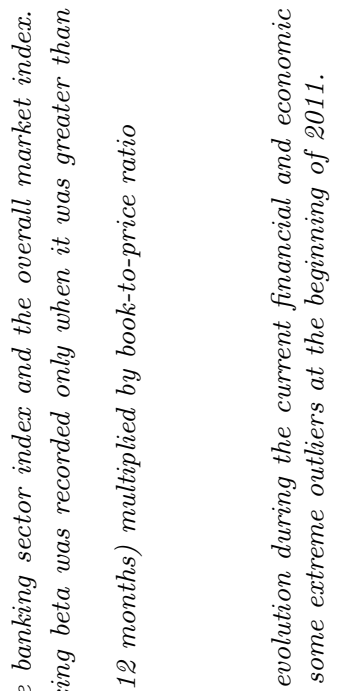

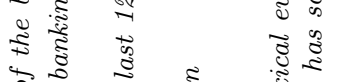

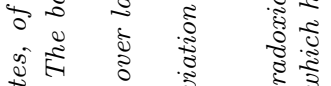

๘.

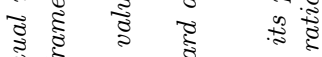

है है छ

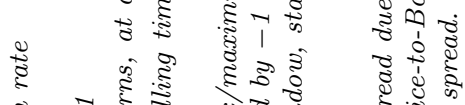

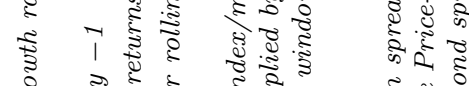

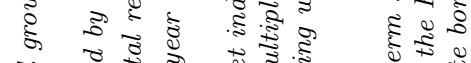

离

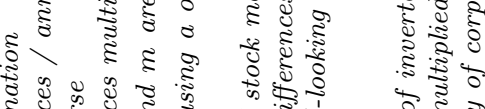

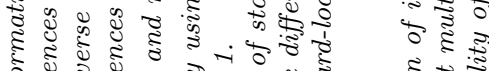

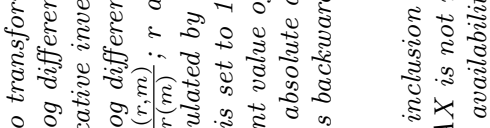

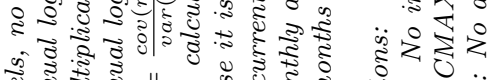

₹

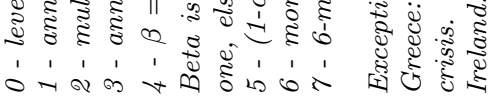




\section{Results from unit root testing}

Table 13: Unit root tests

\begin{tabular}{|c|c|c|c|c|c|c|}
\hline test & & test-stat. & $5 \%$ crit.-val. & & test-stat. & $5 \%$ crit.-val. \\
\hline ERS DF-GLS & \multirow{2}{*}{ ip_aut } & -0.395 & -1.942 & \multirow{2}{*}{ fci_aut } & -3.359 & -1.942 \\
\hline ERS point-optimal & & 0.638 & 3.258 & & 1.120 & 3.259 \\
\hline ERS DF-GLS & \multirow{2}{*}{ ip_bel } & -3.981 & -1.942 & \multirow{2}{*}{ fci_bel } & -2.566 & -1.942 \\
\hline ERS point-optimal & & 0.114 & 3.258 & & 2.179 & 3.259 \\
\hline ERS DF-GLS & \multirow{2}{*}{ ip_fin } & -0.865 & -1.942 & \multirow{2}{*}{ fci_fin } & -2.901 & -1.942 \\
\hline ERS point-optimal & & 0.231 & 3.259 & & 1.564 & 3.259 \\
\hline ERS DF-GLS & \multirow{2}{*}{ ip_fra } & -3.648 & -1.942 & \multirow{2}{*}{ fci_fra } & -3.351 & -1.942 \\
\hline ERS point-optimal & & 0.351 & 3.259 & & 1.285 & 3.259 \\
\hline ERS DF-GLS & \multirow{2}{*}{ ip_ger } & -5.627 & -1.942 & \multirow{2}{*}{ fci_ger } & -3.958 & -1.942 \\
\hline ERS point-optimal & & 0.352 & 3.259 & & 0.761 & 3.259 \\
\hline ERS DF-GLS & \multirow{2}{*}{ ip_gre } & -2.132 & -1.942 & \multirow{2}{*}{ fci_gre } & -2.442 & -1.942 \\
\hline ERS point-optimal & & 0.012 & 3.259 & & 2.480 & 3.259 \\
\hline ERS DF-GLS & \multirow{2}{*}{ ip_ire } & -31.178 & -1.942 & \multirow{2}{*}{ fci_ire } & -0.417 & -1.942 \\
\hline ERS point-optimal & & 0.113 & 3.259 & & 11.394 & 3.259 \\
\hline ERS DF-GLS & \multirow{2}{*}{ ip_ita } & -3.675 & -1.942 & \multirow{2}{*}{ fci_ita } & -1.986 & -1.942 \\
\hline ERS point-optimal & & 0.628 & 3.258 & & 3.630 & 3.259 \\
\hline ERS DF-GLS & \multirow{2}{*}{ ip_nld } & -1.054 & -1.942 & \multirow{2}{*}{ fci_nld } & -3.721 & -1.942 \\
\hline ERS point-optimal & & 0.236 & 3.259 & & 0.934 & 3.259 \\
\hline ERS DF-GLS & \multirow{2}{*}{ ip_prt } & -0.542 & -1.942 & \multirow{2}{*}{ fci_prt } & -1.437 & -1.942 \\
\hline ERS point-optimal & & 0.184 & 3.259 & & 5.126 & 3.259 \\
\hline ERS DF-GLS & \multirow{2}{*}{ ip_esp } & -0.951 & -1.942 & \multirow{2}{*}{ fci_esp } & -1.188 & -1.942 \\
\hline ERS point-optimal & & 0.638 & 3.259 & & 6.094 & 3.259 \\
\hline
\end{tabular}




\section{Non-linearities over time}

Table 14: Excluded time periods for rolling linearity tests and IRFs

\begin{tabular}{l|l}
\hline \hline & Excluded time periods due to unstable results \\
\hline AUT & - \\
BEL & $1995 \mathrm{M} 01-1998 \mathrm{M} 12,2008 \mathrm{M} 09-2009 \mathrm{M} 02,2009 \mathrm{M} 06,2011 \mathrm{M} 08-2013 \mathrm{M} 01$ \\
ESP & $2011 \mathrm{M} 10-2013 \mathrm{M} 01$ \\
FIN & - \\
FRA & $2008 \mathrm{M} 09-2008 \mathrm{M} 11,2011 \mathrm{M} 11$ \\
GER & $2008 \mathrm{M} 09-2009 \mathrm{M} 01$ \\
GRE & $1995 \mathrm{M} 01-1998 \mathrm{M} 01$ \\
ITA & $1995 \mathrm{M} 01-1995 \mathrm{M} 04,1995 \mathrm{M} 06,2011 \mathrm{M} 12,2012 \mathrm{M} 04$ \\
NDL & $2008 \mathrm{M} 09-2008 \mathrm{M} 11,2009 \mathrm{M} 04$ \\
PRT & $2011 \mathrm{M} 08-2013 \mathrm{M} 01$ \\
\hline
\end{tabular}

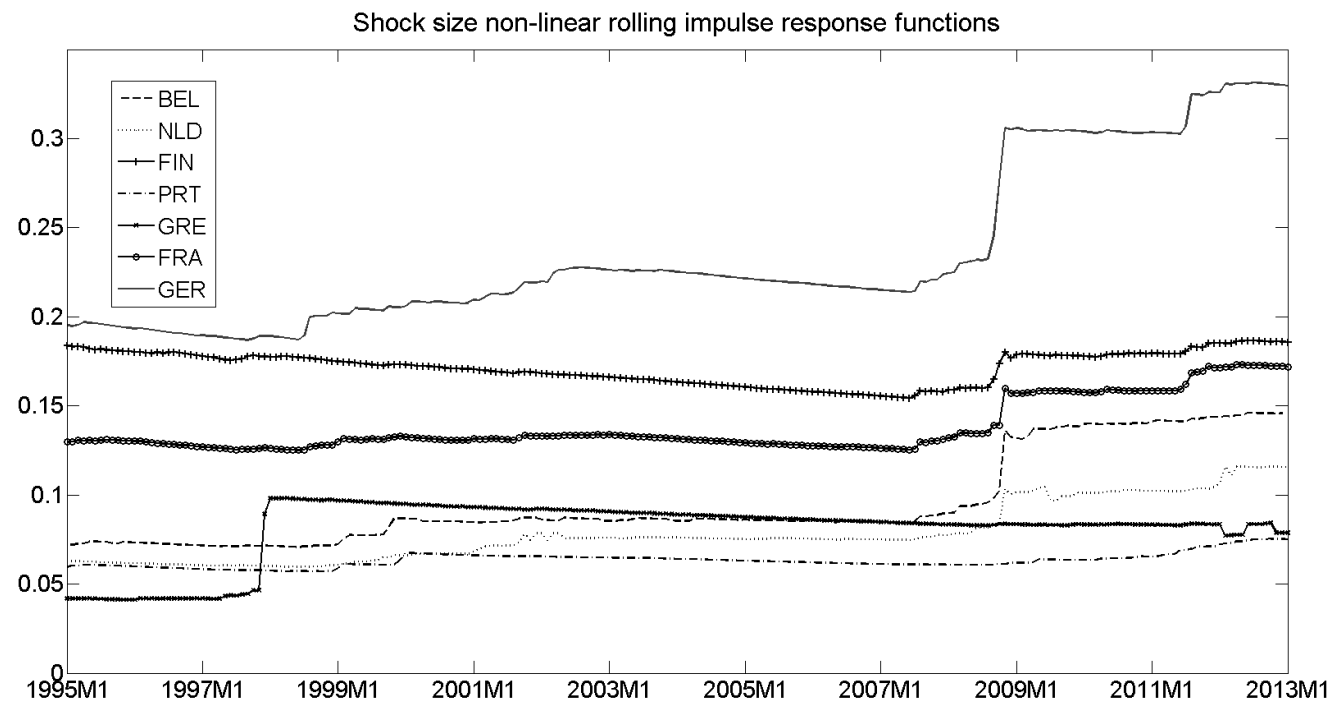

Figure 12: Shock size of FCI 
Average over accumulated response of IP after normalized shock in $\mathrm{FCl}$, low stress regime, FRA

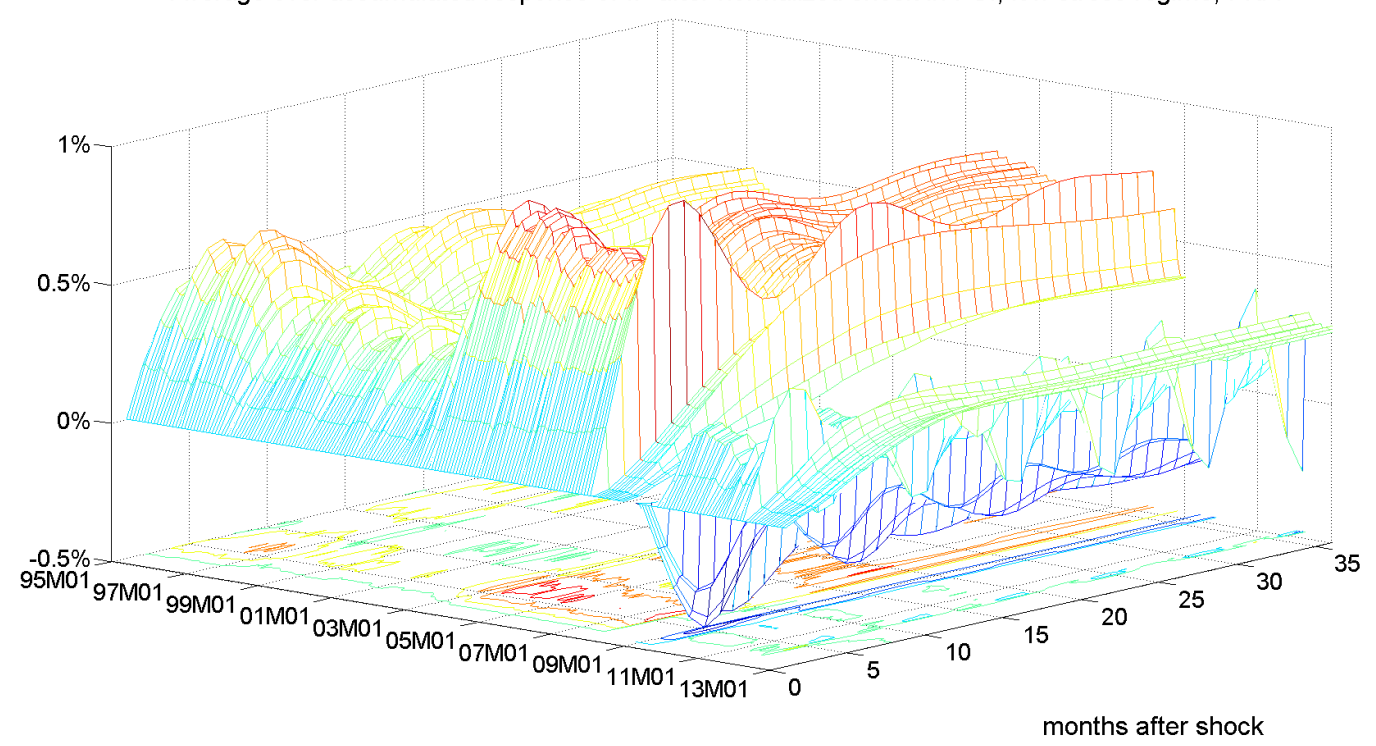

Figure 13: Rolling IRFs of IP, France, normalized shock, low stress regime

Average over accumulated response of IP after normalized shock in $\mathrm{FCl}$, high stress regime, FRA

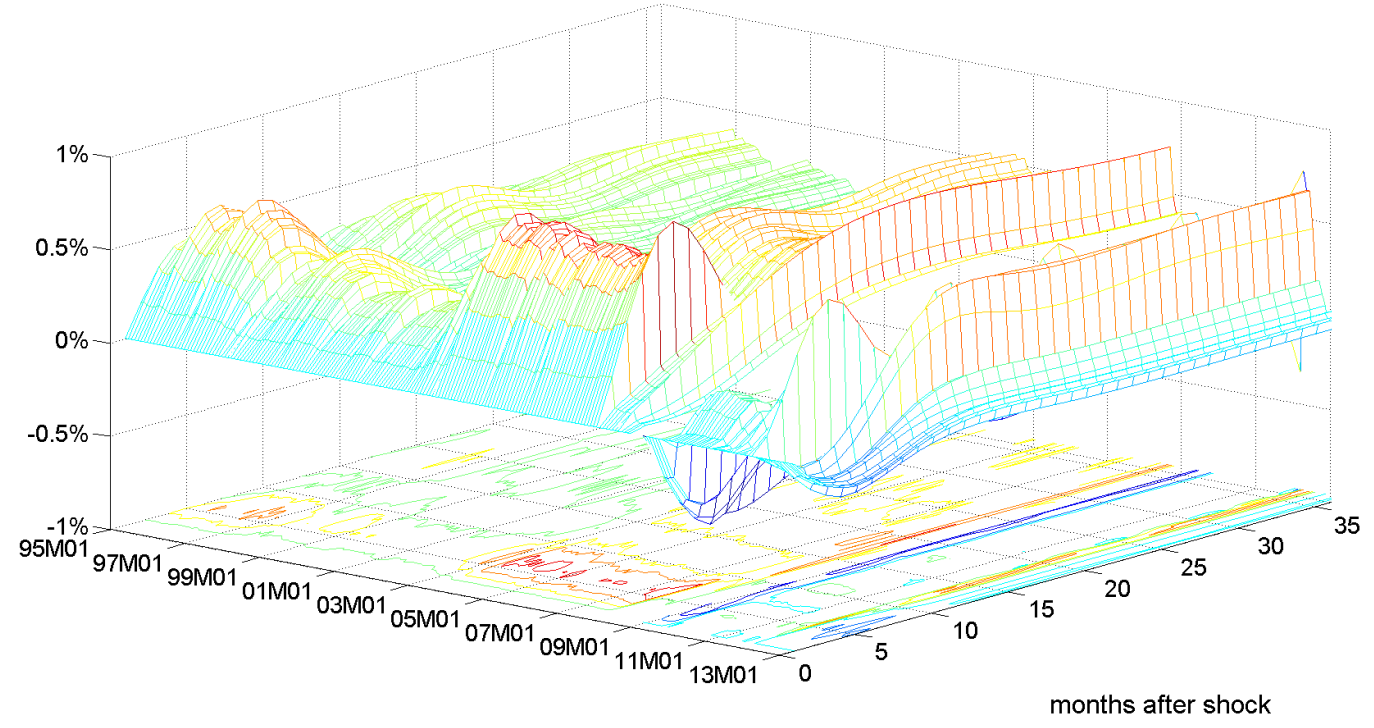

Figure 14: Rolling IRFs of IP, France, normalized shock, high stress regime 


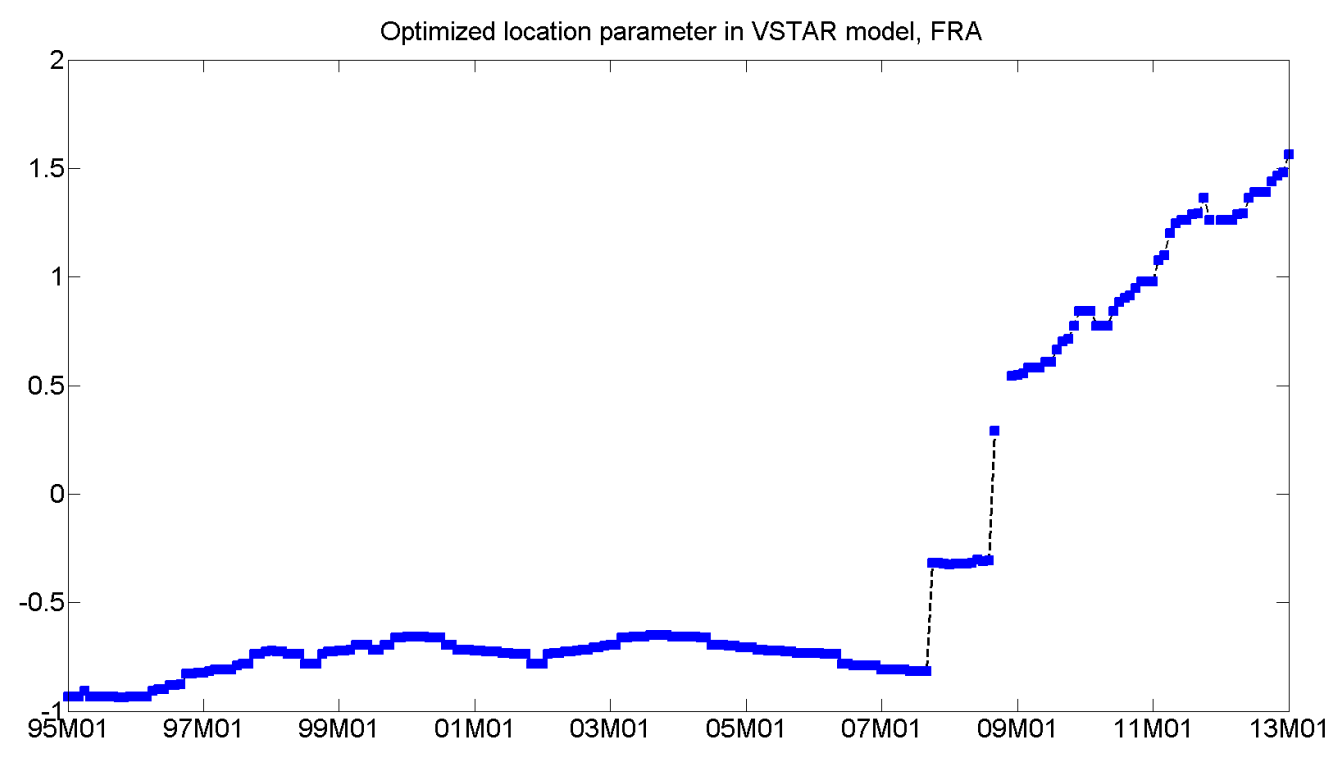

Figure 15: Optimized location parameter VSTAR model, France

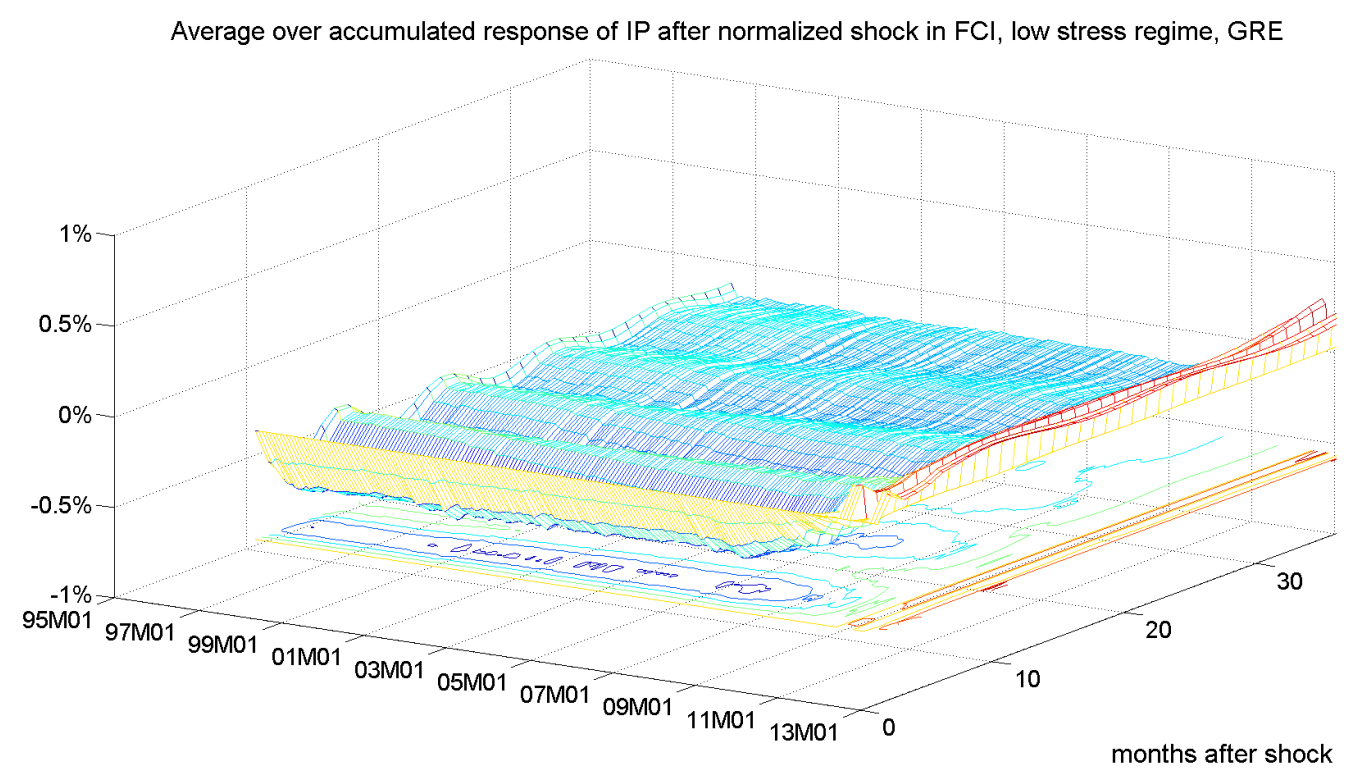

Figure 16: Rolling IRFs of IP, Greece, normalized shock, low stress regime 


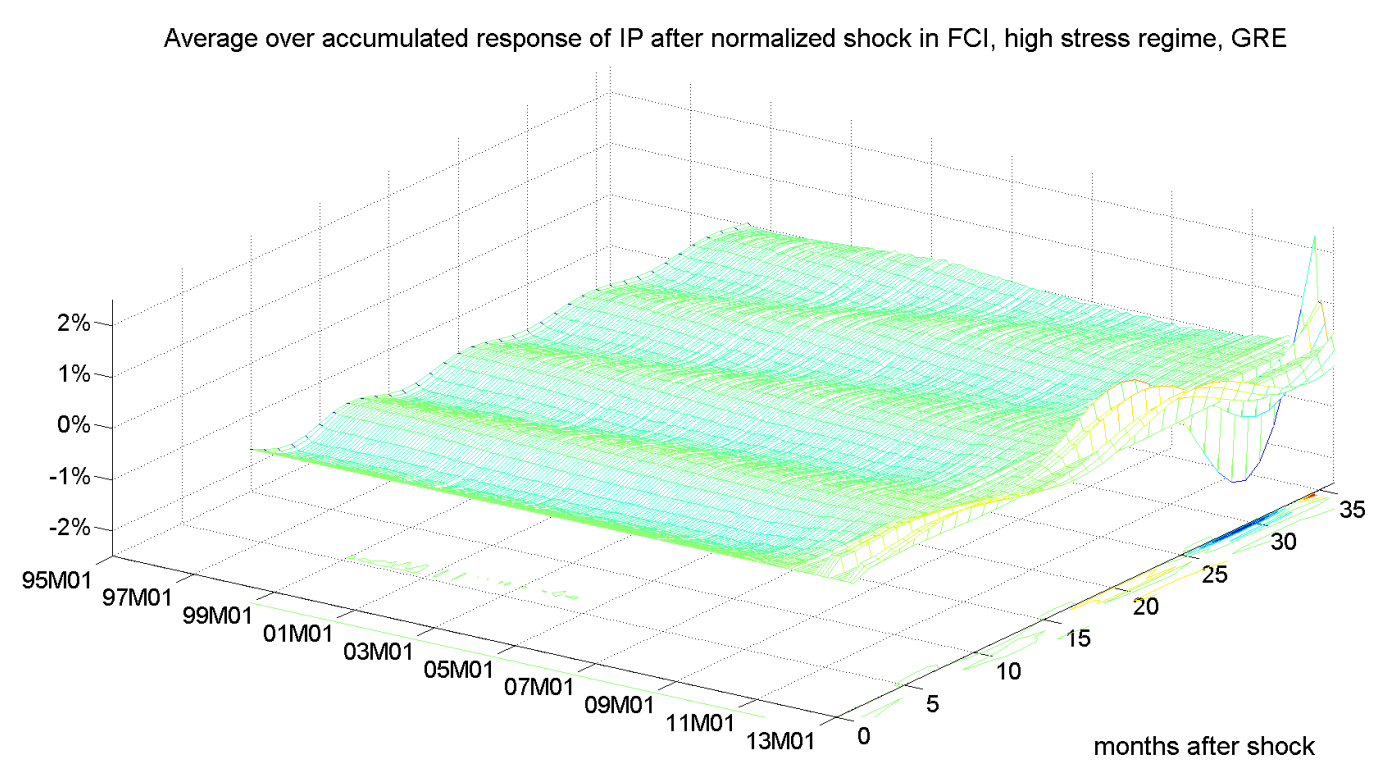

Figure 17: Rolling IRFs of IP, Greece, normalized shock, high stress regime

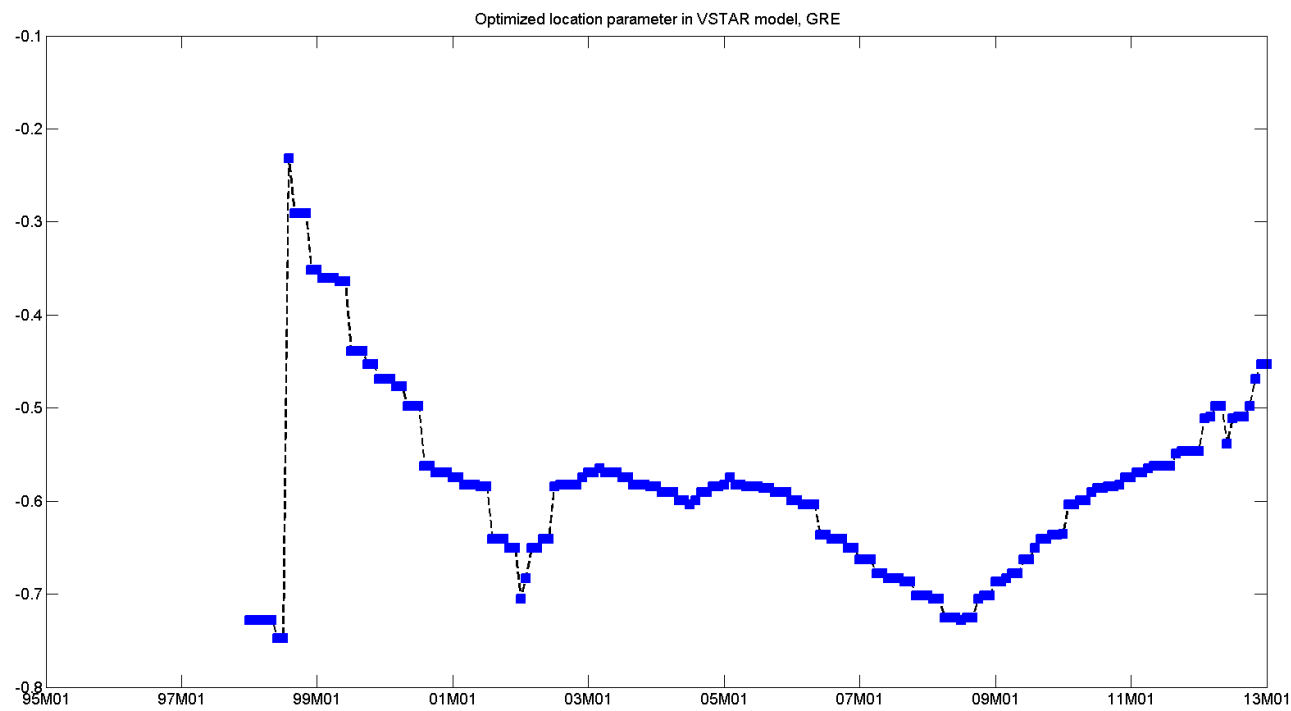

Figure 18: Optimized location parameter VSTAR model, Greece 


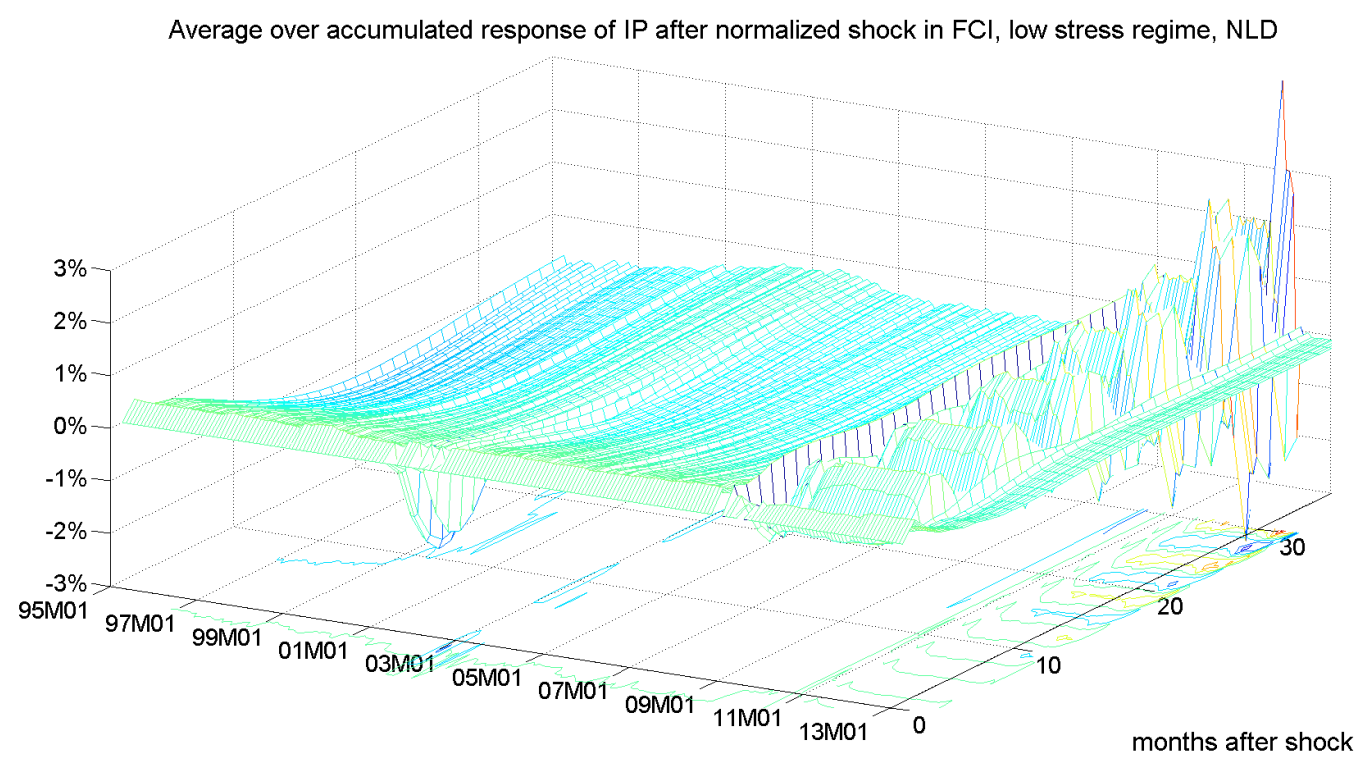

Figure 19: Rolling IRFs of IP, Netherlands, normalized shock, low stress regime

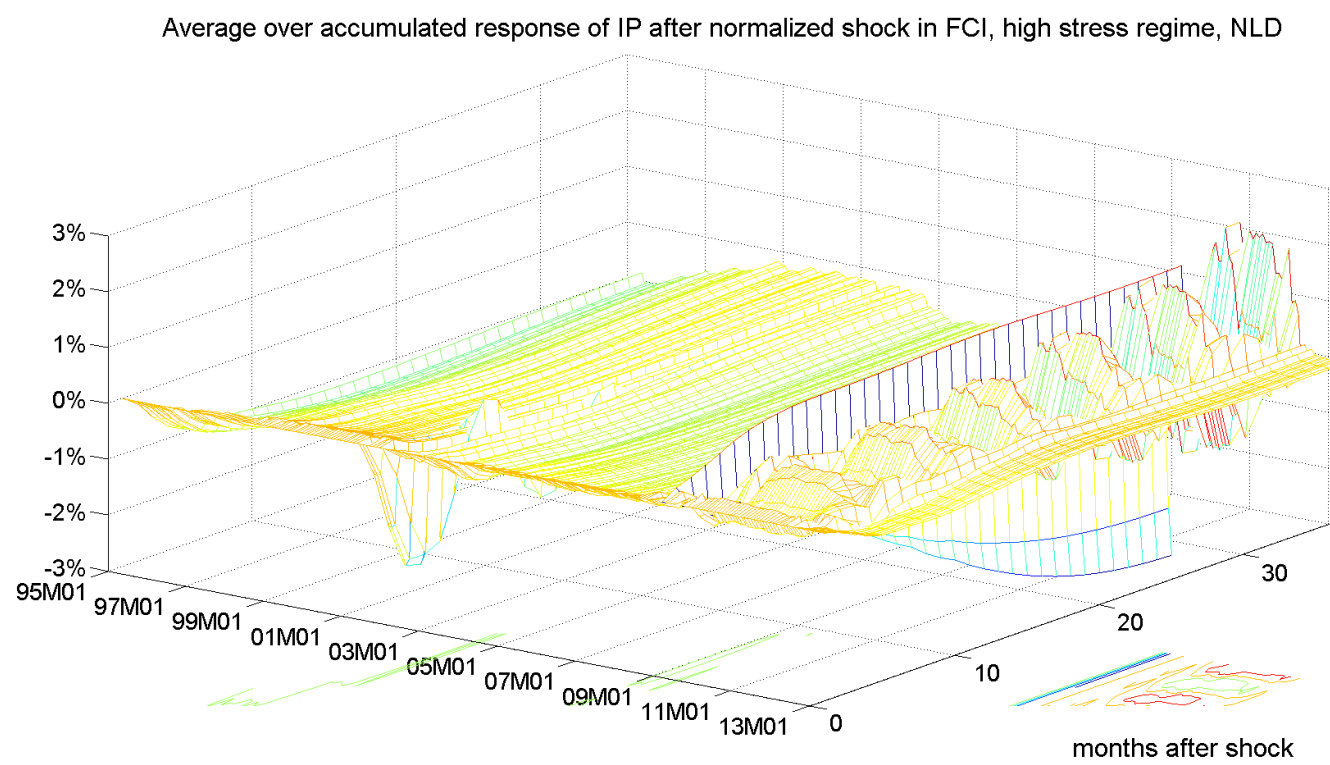

Figure 20: Rolling IRFs of IP, Netherlands, normalized shock, high stress regime 


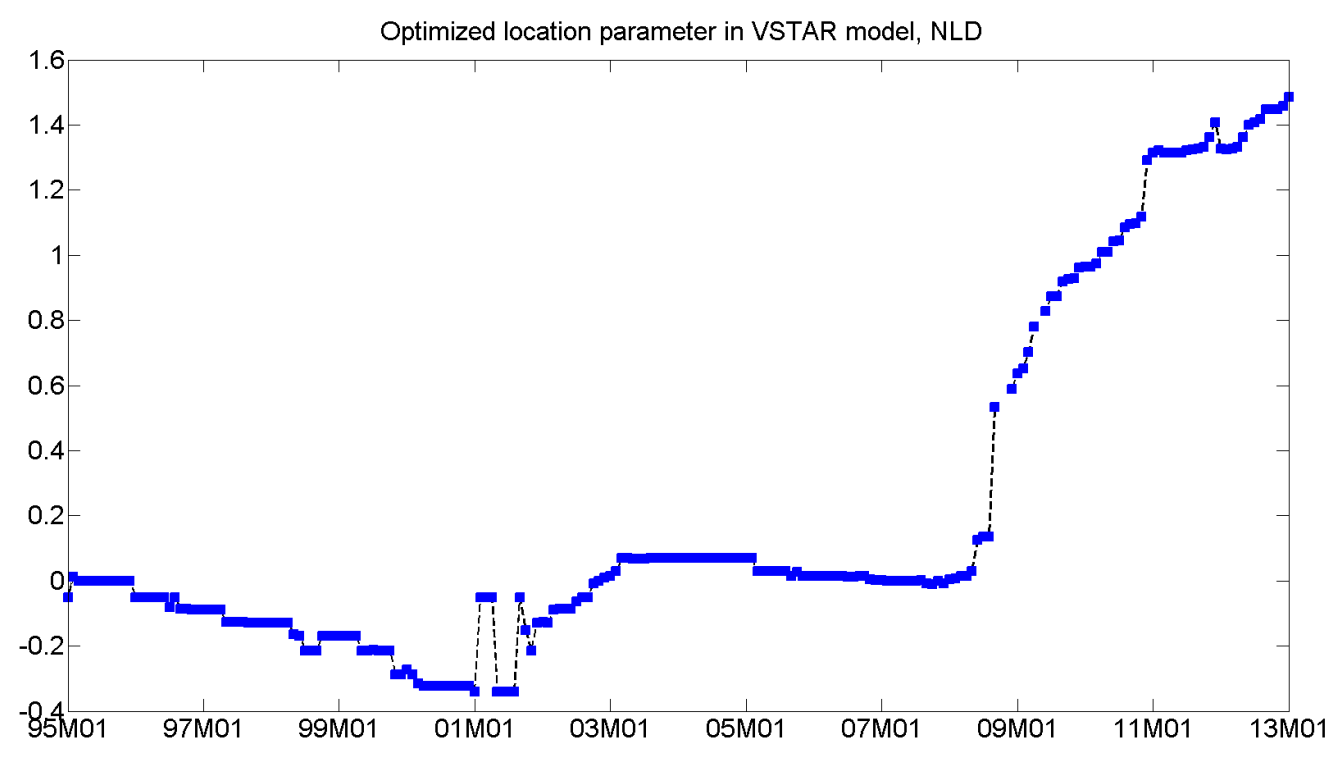

Figure 21: Optimized location parameter VSTAR model, Netherlands

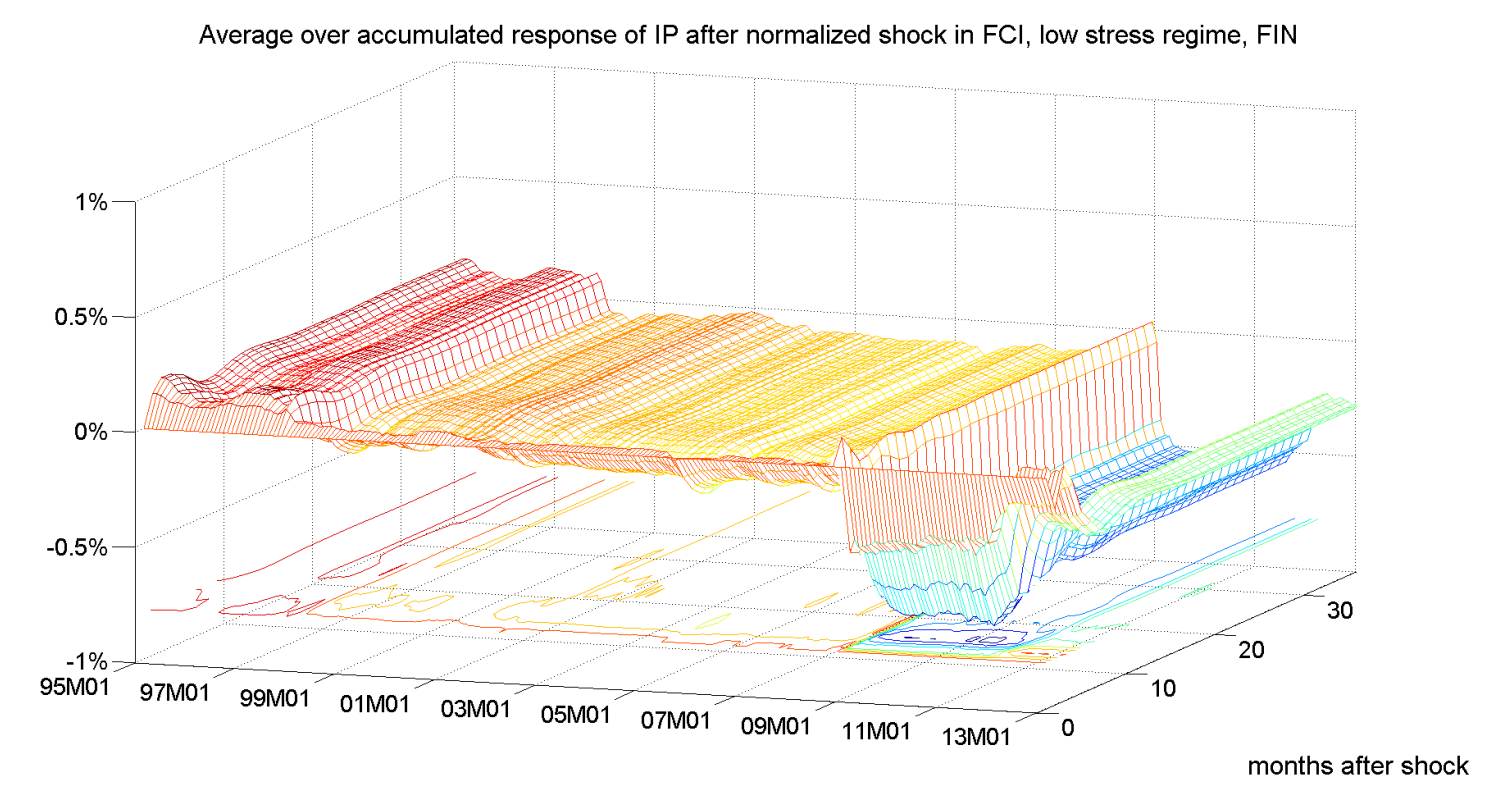

Figure 22: Rolling IRFs of IP, Finland, normalized shock, low stress regime 


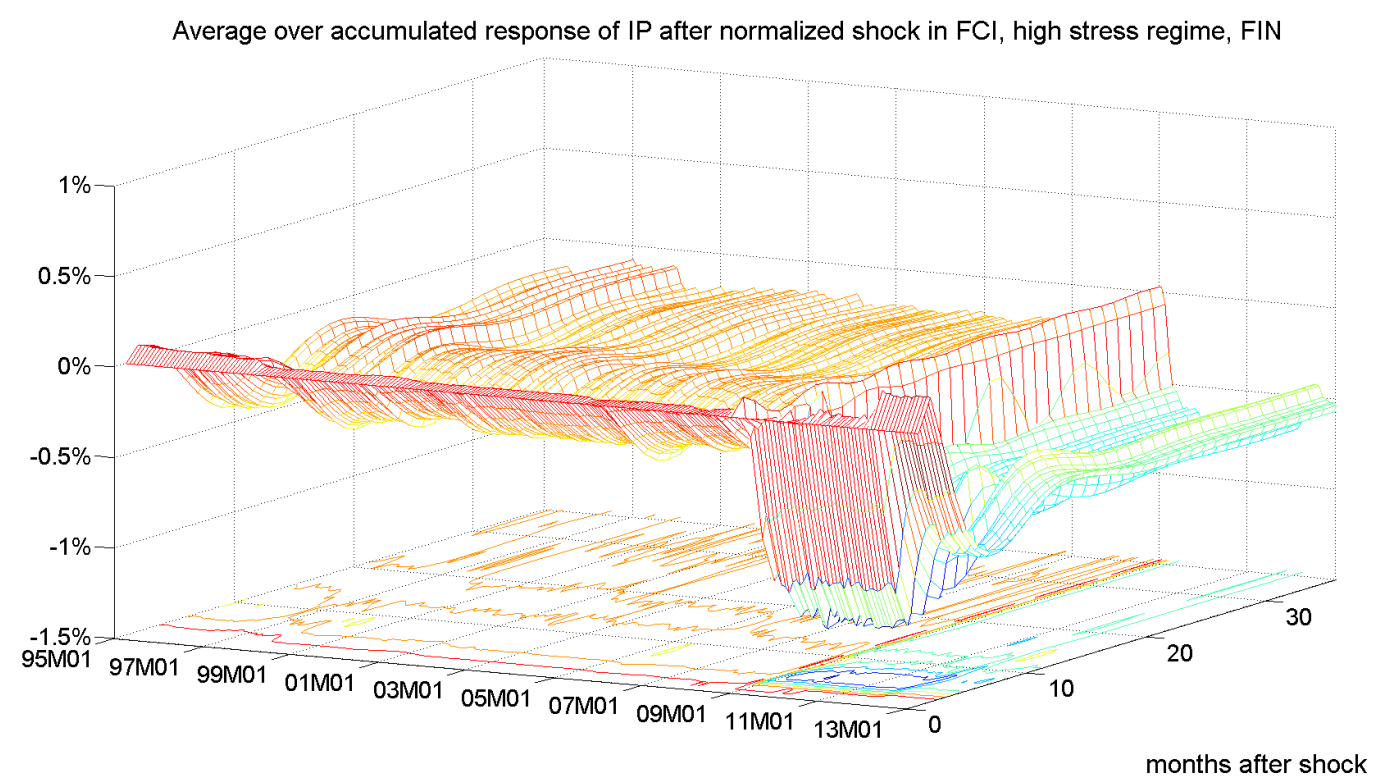

Figure 23: Rolling IRFs of IP, Finland, normalized shock, high stress regime

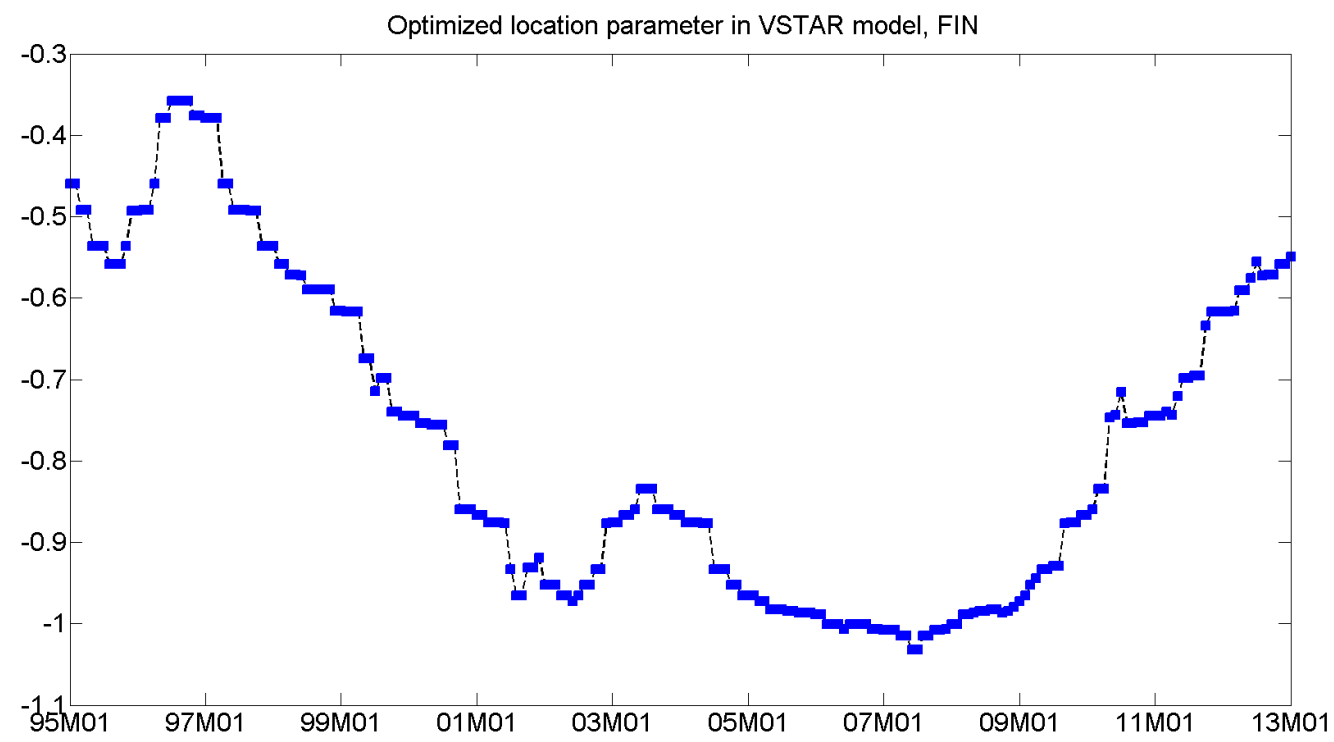

Figure 24: Optimized location parameter VSTAR model, Finland 
Average over accumulated response of IP after normalized shock in $\mathrm{FCl}$, low stress regime, $\mathrm{BEL}$

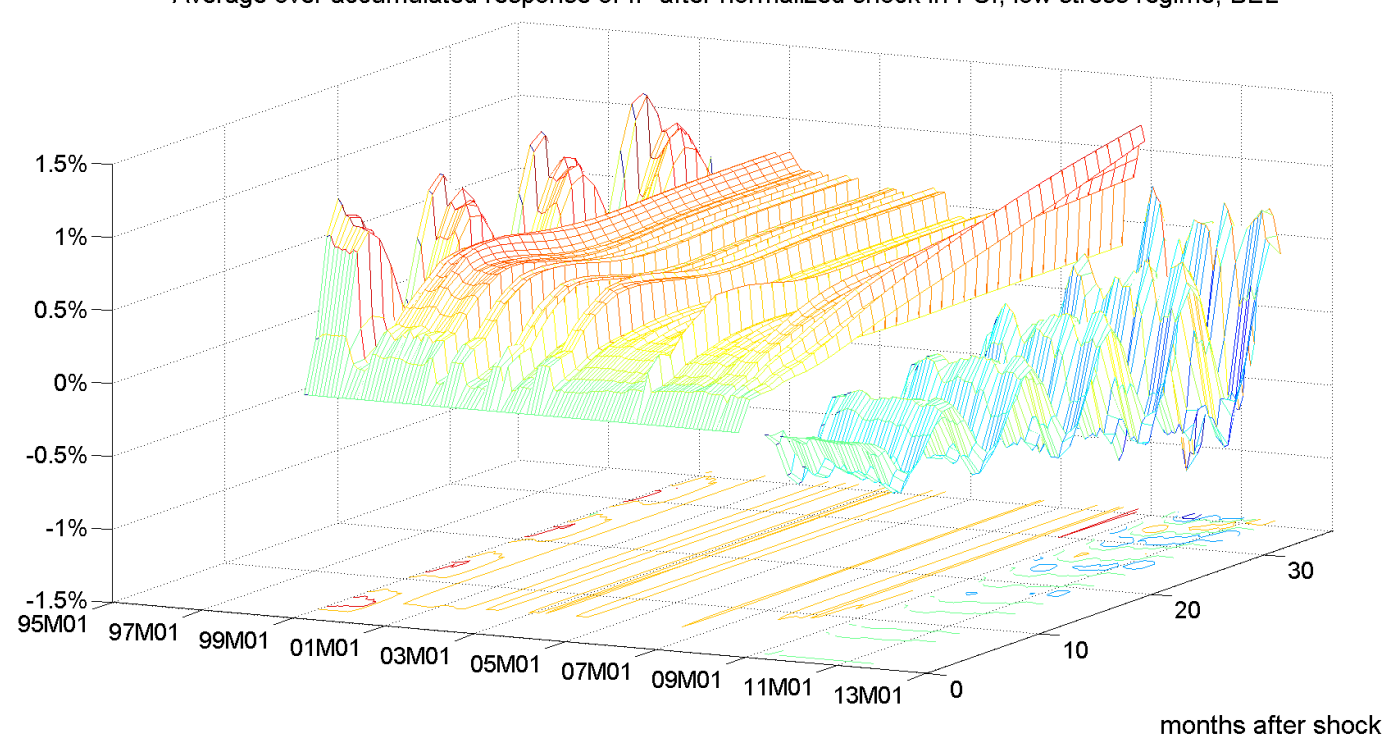

Figure 25: Rolling IRFs of IP, Belgium, normalized shock, low stress regime

Average over accumulated response of IP after normalized shock in $\mathrm{FCl}$, high stress regime, $\mathrm{BEL}$

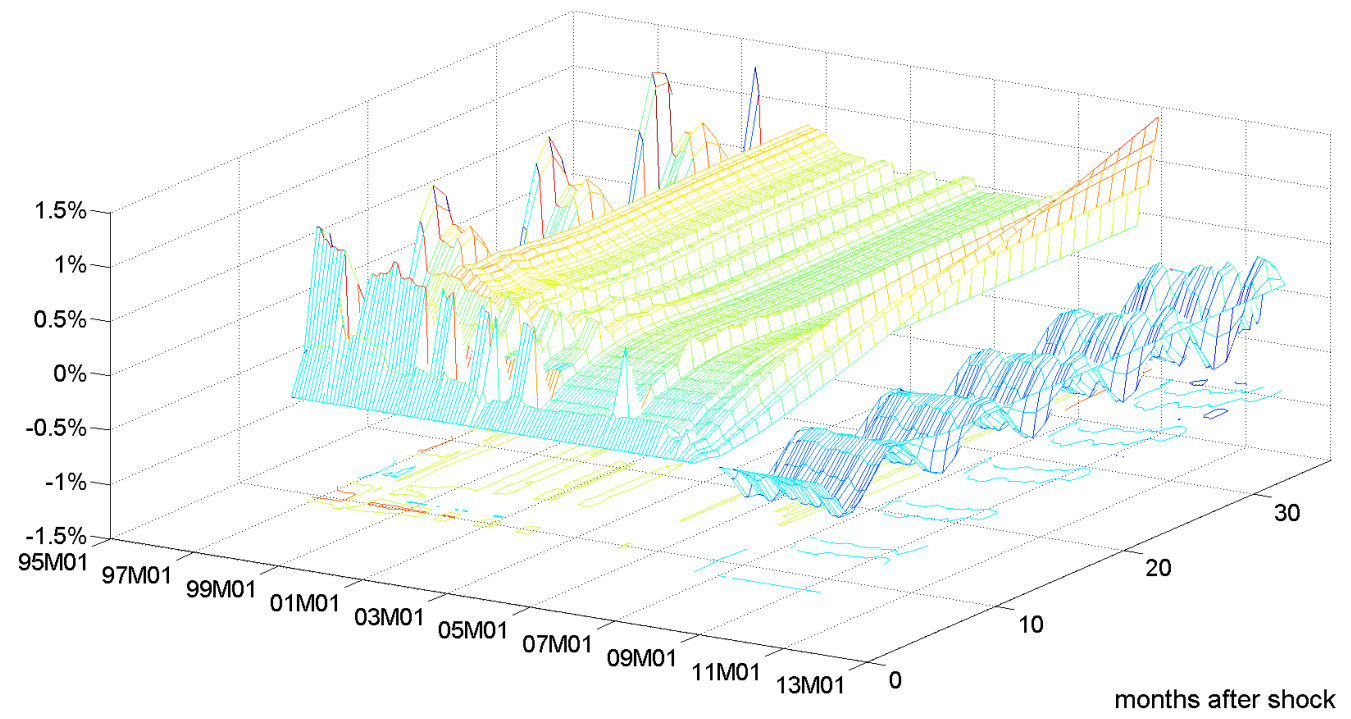

Figure 26: Rolling IRFs of IP, Belgium, normalized shock, high stress regime 


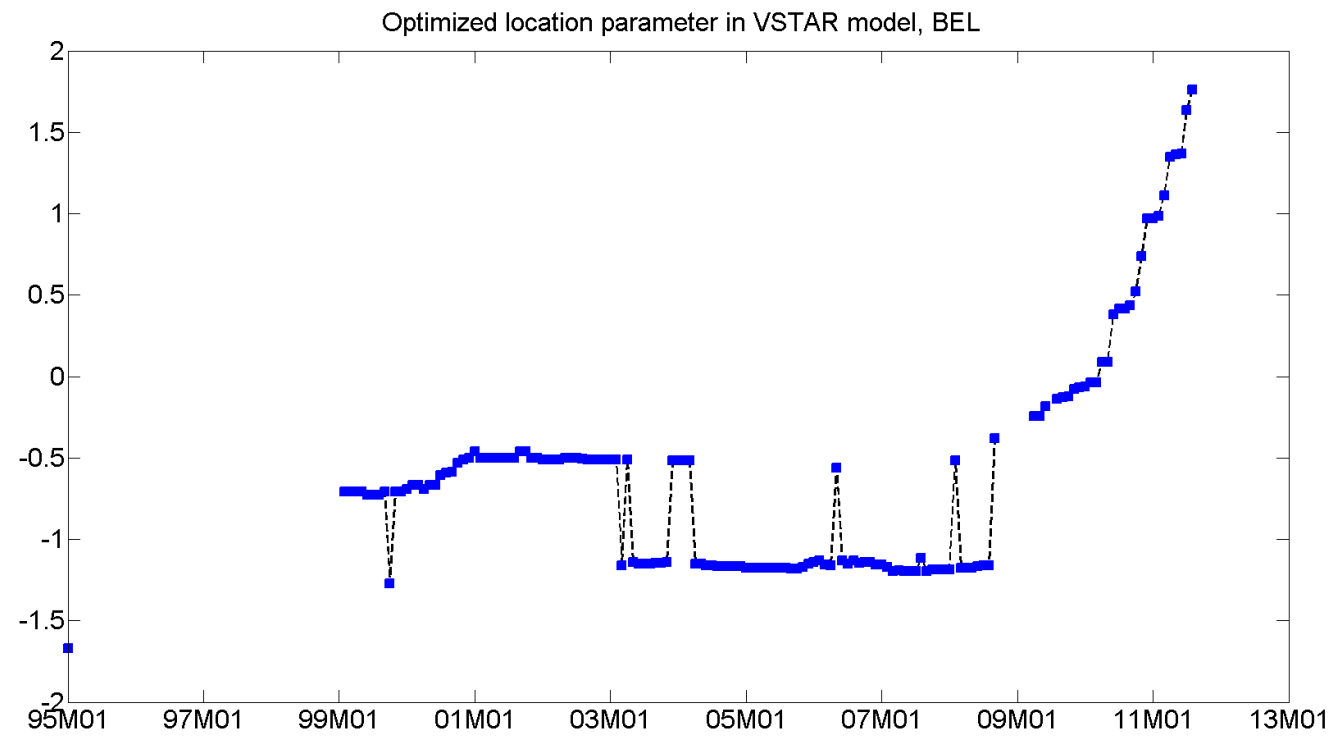

Figure 27: Optimized location parameter VSTAR model, Belgium 


\section{References}

Aboura, Sofiane and Björn van Roye, "Financial stress and economic dynamics: an application to France," Kiel Working Papers 1834, Kiel Institute for the World Economy March 2013.

Adrian, Tobias and Hyun Song Shin, "Money, Liquidity, and Monetary Policy," American Economic Review, May 2009, 99 (2), 600-605.

_ , Emanuel Moench, and Hyun Song Shin, "Macro Risk Premium and Intermediary Balance Sheet Quantities," IMF Economic Review, August 2010, 58 (1), 179-207.

Benati, Luca, "Why Are Recessions Associated With Financial Crises Different?," Working Paper, University of Bern 2013.

Bernanke, Ben S., Mark Gertler, and Simon Gilchrist, "The financial accelerator in a quantitative business cycle framework," in J. B. Taylor and M. Woodford, eds., Handbook of Macroeconomics, Vol. 1 of Handbook of Macroeconomics, Elsevier, 1999, chapter 21, pp. 1341-1393.

Bijlsma, Michiel J. and Gijsbert T.J. Zwart, "The Chaning Landscape of Financial Markets in Europe, the United States and Japan," Working Paper, BRUEGEL Working Paper 2013/02, 2013.

Blanchard, Olivier and Stanley Fischer, Lectures on Macroeconomics, 1 ed., Vol. 1, The MIT Press, 1989.

Blanchard, Olivier J. and Daniel Leigh, "Growth Forecast Errors and Fiscal Multipliers," NBER Working Papers 18779, National Bureau of Economic Research February 2013.

Bohn, Henning, "Are stationarity and cointegration restrictions really necessary for the intertemporal budget constraint?," Journal of Monetary Economics, October 2007, 54 (7), 1837-1847.

Boissay, Frederic, Fabrice Collard, and Frank Smets, "Booms and Systemic Banking Crises," Working Paper Series 1514, European Central Bank February 2013.

Bolton, Patrick and Olivier Jeanne, "Sovereign Default Risk and Bank Fragility in Financially Integrated Economies," IMF Economic Review, 2011, 59 (2), 162-194.

Brunnermeier, Markus K. and Martin Oehmke, "Bubbles, Financial Crises, and Systemic Risk," NBER Working Papers 18398, National Bureau of Economic Research September 2012. 
- and Yuliy Sannikov, "A macroeconomic model with a financial sector," American Economic Review, June 2013, forthcoming.

Camacho, Maximo, "Vector Smooth Transition Regression Models for US GDP and the Composite Index of Leading Indicators," Journal of Forecasting, 2004, 23 (3), 173 - 196.

Charpe, Matthieu, Peter Flaschel, Hans-Martin Krolzig, Christian R. Proa no, Willi Semmler, and Daniele Tavani, "Credit Driven Investment, Heterogenous Labor Markets and the NAIRU in a Keynesian Model of Endogneous Business Flucatuations," manuskript, forthcoming Festschrift for M. Aoki 2013.

Christiano, Lawrence, Martin Eichenbaum, and Sergio Rebelo, "When Is the Government Spending Multiplier Large?," Journal of Political Economy, 2011, 119 (1), 78 - 121 .

Corsetti, Giancarlo, Keith Kuester, André Meier, and Gernot J. Müller, "Sovereign Risk, Fiscal Policy, and Macroeconomic Stability," The Economic Journal, 2013, 123 (566), F99-F132.

Davig, Troy and Craig Hakkio, "What is the effect of financial stress on economic activity," Economic Review, 2010, (Q II), 35-62.

Doz, Catherine, Domenico Giannone, and Lucrezia Reichlin, "A two-step estimator for large approximate dynamic factor models based on Kalman filtering," Journal of Econometrics, September 2011, 164 (1), 188-205.

Eggertsson, Gauti B. and Paul Krugman, "Debt, Deleveraging, and the Liquidity Trap: A Fisher-Minsky-Koo Approach," The Quarterly Journal of Economics, 2012, $127(3), 1469-1513$.

Elliott, Graham, Thomas J. Rothenberg, and James H. Stock, "Efficient Tests for an Autoregressive Unit Root," Econometrica, 1996, 64 (4), 813-836.

Ernst, Ekkehard and Willi Semmler, "Labor Market, Credit Market and Macroeconomic Dynamics," Manuscript, International Labor Organization 2012.

Galí, Jordi, J. David López-Salido, and Javier Vallés, "Understanding the Effects of Government Spending on Consumption," Journal of the European Economic Association, 03 2007, 5 (1), 227-270.

Geanakoplos, John, Panel Statement - Endogenous leverage and default Chapters, European Central Bank,

- and J. Doyne Farmer, "The Virtues and Vices of Equilibrium and the Future of Financial Economics," Complexity, 2009, 14 (3), 11-38. 
Gilchrist, Simon and Egon Zakrajšek, "Credit Spreads and Business Cycle Fluctuations," American Economic Review, June 2012, 102 (4), 1692-1720.

Godfrey, Leslie George and Andrew R. Tremayne, "The wild bootstrap and heteroskedasticity-robust tests for serial correlation in dynamic regression models," Computational Statistics $\&$ Data Analysis, April 2005, 49 (2), 377-395.

Gorton, Gary B., Slapped by the Invisible Hand: The Panic of 2007 number 9780199734153. In 'OUP Catalogue.', Oxford University Press, 2010.

Grauwe, Paul De, "The Governance of a Fragile Eurozone," Australian Economic Review, 2012, 45 (3), 255-268.

Grüne, Lars and Jürgen Pannek, Nonlinear Model Predictive Control, Springer, 2011.

_ and Willi Semmler, "Using dynamic programming with adaptive grid scheme for optimal control problems in economics," Journal of Economic Dynamics and Control, December 2004, 28 (12), 2427-2456.

_, _, and Marleen Stieler, "Using Nonlinear Model Predictive Control for Dynamic Decision Problems In Economics," Working Paper 2013.

Hayashi, Fumio, Econometrics, 1 ed., Vol. 1, Princeton University Press, 2000.

Holló, Dániel, Manfred Kremer, and Marco Lo Duca, "CISS - a composite indicator of systemic stress in the financial system," Working Paper Series 1426, European Central Bank March 2012.

Hubrich, Kirstin and Robert J. Tetlow, "Financial stress and economic dynamics: the transmission of crises," Finance and Economics Discussion Series 2012-82, Board of Governors of the Federal Reserve System (U.S.) 2012.

_ and Timo Teräsvirta, "Thresholds and Smooth Transitions in Vector Autoregressive Models," Research Paper 2013-18, CREATES 2013.

_, Antonello D’Agostino, Maria Ĉervená, Matteo Ciccarelli, Paolo Guarda, Markus Haavio, Philippe Jeanfils, Caterina Mendicino, Eva Ortega, Maria Teresa Valderrama, and Marianna V. Endrész, "Financial shocks and the macroeconomy: heterogeneity and non-linearities," Occasional Paper Series 143, European Central Bank February 2013.

Hyndman, Rob J., "Computing and Graphing Highest Density Regions," The American Statistician, 1996, 50 (2), 120-126. 
Jordà, Oscar, Moritz Schularick, and Alan M. Taylor, "When Credit Bites Back: Leverage, Business Cycles, and Crises," NBER Working Papers 17621, National Bureau of Economic Research November 2011.

Kliesen, Kevin L., Michael T. Owyang, and E. Katarina Vermann, "Disentangling Diverse Measures: A Survey of Financial Stress Indexes," 2012, 94 (5).

Koop, Gary, M. Hashem Pesaran, and Simon M. Potter, "Impulse Response Analysis in Nonlinear Multivariate Models," Journal of Econometrics, 1996, 74 (1), $119-147$.

Lütkepohl, Helmut, New Introduction to Multiple Time Series Analysis, Berlin: Springer Verlag, 2005.

Mittnik, Stefan and Willi Semmler, "Regime dependence of the fiscal multiplier," Journal of Economic Behavior \& Organization, 2012, 83 (3), 502-522.

_ and _ , "The real consequences of financial stress," Journal of Economic Dynamics and Control, 2013, 37 (8), 1479 - 1499.

Neely, Christopher J., "The mysterious Greek yield curve," Economic Synopses, 2012, (6).

Roch, F. and H. Uhlig, "The Dynamics of Sovereign Debt Crises and Bailouts," Working Paper, University of Chicago 2012.

Schleer, Frauke, "Finding starting-values for maximum likelihood estimation of Vector STAR models," unpublished working paper, ZEW 2013.

Schularick, Moritz and Alan M. Taylor, "Credit Booms Gone Bust: Monetary Policy, Leverage Cycles, and Financial Crises, 1870-2008," American Economic Review, April 2012, $102(2), 1029-61$.

Schwarz, Gideon, "Estimating the Dimension of a Model," The Annals of Statistics, 1978, $6(2), 461-464$.

Schwert, G. William, "Tests for Unit Roots: A Monte Carlo Investigation," Journal of Business \&f Economic Statistics, 1989, 7 (2), 147 - 159.

Semmler, Willi and Lucas Bernard, "Boombust cycles: Leveraging, complex securities, and asset prices," Journal of Economic Behavior \& Organization, 2012, 81 (2), $442-465$.

- and Pu Chen, "Financial Stress, Regime Switching and Macrodynamics: Theory and Empirics for the US, EU and Non-EU Countries," Economics Discussion Paper, The Open Access, Open Assessment E Journal, No 2013-24 2013. 
Skalin, Joakim and Timo Teräsvirta, "Modeling Asymmetries and Moving Equilibria in Unemployment Rates," Macroeconomic Dynamics, 2002, 6 (2), 202 - 241.

Stein, Jerome L., Stochastic Optimal Control and the U.S. Financial Debt Crisis, Heidelberg/New York, Springer, 2012.

Stiglitz, Joseph E. and Bruce Greenwald, Towards a New Paradigm in Monetary Economics, Cambridge University Press, 2003.

Teräsvirta, Timo, "Specification, Estimation, and Evaluation of Smooth Transition Autoregressive Models," Journal of the American Statistical Association, 1994, 89 (425), $208-218$.

_ , "Modelling Economic Relationships with Smooth Transition Regressions," in A. Ullah and D. E. A. Giles, eds., Handbook of Applied Economic Statistics, New York: M. Dekker, Inc., 1998, pp. 507-552.

_ , "Smooth Transition Regression Modeling," in Lütkepohl H. and M. Krätzig, eds., Applied Time Series Econometrics, Cambridge: Cambridge University Press, 2004, pp. $222-242$.

- and Yukai Yang, "Specification, Estimation and Evaluation of Vector Smooth Transition Autoregressive Models with Applications," unpublished working paper, CREATES Research Paper 2013a.

_ and _ , "Linearity and Misspecification Tests for Vector Smooth Transition Regression Models," unpublished working paper, CREATES Research Paper 2013b.

_, Dag Tjostheim, and Clive W. J. Granger, Modelling Nonlinear Economic Relationships, Oxford: Oxford University Press, 2010.

Tobin, James, "Keynesian Models of Recession and Depression," American Economic Review, May 1975, 65 (2), 195-202.

van Roye, Björn, "Financial stress and economic activity in Germany and the Euro Area," Kiel Working Papers 1743, Kiel Institute for the World Economy November 2011.

Weise, Charles L., "The Asymmetric Effects of Monetary Policy: A Nonlinear Vector Autoregression Approach," Journal of Money, Credit and Banking, 1999, 31 (1), 85 108.

Woodford, Michael, "Simple Analytics of the Government Expenditure Multiplier," American Economic Journal: Macroeconomics, January 2011, 3 (1), 1-35. 